\title{
Dinámica del empleo en el centro tradicional de negocios de Toluca (México), 2010-2018: cambio y participación espacial
}

\section{Dynamics of Employment at the Traditional Business Center of Toluca (Mexico), 2010-2018: Spatial Shift-Share Analysis}

\author{
Luis Giovanni Ramírez Sánchez* (D) https://orcid.org/0000-0003-0509-3413 \\ Tania Chávez Soto ** (iD https://orcid.org/0000-0002-6884-0415 \\ Carlos Garrocho Rangel $^{\star * *}$ (iD) https://orcid.org/0000-0001-9181-3151
}

\begin{abstract}
Resumen
Objetivo: explicar la dinámica del empleo en el centro tradicional de negocios del área metropolitana de Toluca entre 2010 y 20I8. Metodología: análisis de cambio y participación tradicional no espacial y espacial de los I7 sectores que operan en dicho centro y se detallan dos sectores clave: comercio de minoristas y servicios de profesionales. Resultados: el centro tradicional de negocios está en decadencia económica y como lugar de funciones centrales. Se identifican microespacios y sectores estratégicos que deben ser atendidos para recuperar y fortalecer las funciones centrales de dicho centro y de otros centros exitosos similares, de los cuales depende la vitalidad de la zona de estudio. Se identifican las causas de este desempeño diferenciado en la escala del centro tradicional de negocios y en la microespacial. Limitaciones: no se esclarecen las causas de las causas de la dinámica del empleo, lo que requiere trabajo de campo. Valor: se incorpora la dimensión espacial al análisis de cambio y participación. Conclusiones: se ofrece información clave para fortalecer el centro tradicional de negocios como lugar de funciones centrales y motor de desarrollo.

Palabras clave: cambio y participación espacial; centro tradicional de negocios; microespacios; Toluca.
\end{abstract}

\begin{abstract}
Objective: to explain the dynamics of employment in the traditional business center of the metropolitan area of Toluca between 2010 and 2018. Methodology: non-spatial and spatial shift-share analysis focused on the 17 sectors that operate in the center and two key sectors - retailing and professional services - are detailed. Results: the center is in economic decline and weakens as a place of central functions. Through the investigation, micro-spaces and strategic sectors were identified as needed for attention to recover and strengthen the center and other successful centers' central functions on which the vitality of the study area depends. The causes of this heterogeneous performance in the center and in the micro-spaces are identified. Limitations: the causes of causes of the employment dynamics are not specified because it requires fieldwork. Value: the incorporation of the spatial dimension to the shift-share analysis. Conclusions: the work offers critical information to strengthen the center as a place of central functions and development engine.

Keywords: spatial shift-share analysis; traditional business center; micro-spaces; Toluca.
\end{abstract}

Cómo citar: Ramírez Sánchez, L. G., Chávez Soto, T., y Garrocho Rangel, C. (202I). Dinámica del empleo en el centro tradicional de negocios de Toluca (México), 20 I0-20 I8: cambio y participación espacial. región y sociedad, 33, el 395. doi: I0.22 I 98/rys202 I/33/I395

*Autor para correspondencia. Cátedras CONACYT-El Colegio Mexiquense, A. C. Seminario: Estudios Estratégicos del Estado de México. Ex-Hacienda Santa Cruz de los Patos s. n., C. P. 51350. Zinacantepec, Estado de México, México. Correo electrónico: Iramirez@cmq.edu.mx

${ }^{\star *}$ El Colegio Mexiquense, A. C. Seminario: Estudios Estratégicos del Estado de México. Ex-Hacienda Santa Cruz de los Patos s. n., C. P. 51350. Zinacantepec, Estado de México, México. Correo electrónico: tchavez@cmq.edu.mx

${ }^{\star \star *}$ El Colegio Mexiquense, A. C. Seminario: Estudios Estratégicos del Estado de México. Ex-Hacienda Santa Cruz de los Patos s. n., C.P. 51350. Zinacantepec, Estado de México, México. Correo electrónico: cfgarrocho@gmail.com

Recibido: 7 de septiembre de 2020

Aceptado: 27 de mayo de 2021

Liberado: 5 de julio de 2021

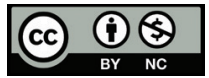

Esta obra está protegida bajo una Licencia

Creative Commons Atribución-No Comercial 4.0 Internacional. 


\section{Introducción}

El objetivo de este artículo es explicar la dinámica del empleo en el centro tradicional de negocios (CTN) del área metropolitana de Toluca (AMT) entre 2010 y 2018. ${ }^{1}$ Las preguntas que se exploran son: ¿cuánto, dónde, en qué sectores, cuándo y por qué cambió el empleo en el CTN y en sus espacios interiores? Los métodos básicos empleados son el análisis de cambio y participación tradicional o no espacial (ACPT) y el análisis de cambio y participación espacial (ACPE).

Se consideran cuatro escalas geográficas: 1) metropolitana, 2) CTN, 3) espacios interiores de éste (a los que aquí se llama microespacios) y 4) conjuntos de microespacios vecinos (zonas vecinales). En el contexto del análisis de cambio y participación, las causas básicas de la dinámica del empleo en el CTN son el impulso/freno: 1) que ejerce el desempeño del mercado laboral de la ciudad sobre el CTN; 2) del comportamiento del mercado laboral del CTN sobre sus microespacios; y 3) que ejercen los microespacios entre sí (Nazara y Hewings, 2003). Estas causas básicas se vinculan con la estructura sectorial, con la especialización económica, con las ventajas competitivas que se registran en cada escala y con las interacciones entre ellas (interacciones directas e indirectas) (Gallo y Kamarianakis, 2011).

Aparte de esta introducción, el texto inicia justificando la importancia de los CTN para el desarrollo socioeconómico de las ciudades latinoamericanas (incluida la AMT). Luego se especifica el marco analítico y la metodología. Se adopta una perspectiva didáctica, porque el proceso de cálculo del ACPE no es simple. Se incluye un diagrama paso a paso de todo el procedimiento. Con el ACPT se hace un primer acercamiento a la evolución del empleo en los 17 sectores que operan en el CTN, lo que permite interpretar mejor los resultados del ACPE en la escala microespacial. Por razones de extensión del texto, sólo se analizan en detalle dos sectores clave: el comercio al por menor y los servicios de profesionales. En la última sección, se presentan las principales conclusiones, algunas recomendaciones y se perfila una agenda de investigación.

Una advertencia: el análisis de cambio y participación (tanto el no espacial como el espacial) permite identificar y cuantificar las causas básicas de la evolución del empleo en una zona de estudio. Sin embargo, no genera información en detalle sobre las causas de las causas, que sólo puede obtenerse mediante estudios en profundidad fuera del alcance de este trabajo. ${ }^{2}$

\section{Marco de referencia}

En la mayoría de los países del mundo, las áreas metropolitanas registran patrones policéntricos o dispersos de empleo (y población), así como pérdida de

\footnotetext{
Toluca es la quinta ciudad más poblada de México. En 2018 tenía 2.3 millones de habitantes.

2 Algunos ejemplos de causas de las causas: seguridad de la zona, calidad de las interacciones empresariales, intensidad innovadora del entorno, condiciones financieras de los negocios, costo del suelo, situación de la infraestructura y del medioambiente, accesibilidad, facilidad de estacionamiento y percepción del futuro de la zona.
} 
competitividad del CTN (central business district o CBD en inglés) (Giuliano, Redfearn, Agarwal, Li y Zhuang, 2007; Simmons, 2013). México no es la excepción (Casado, 2012; Garrocho y Campos, 2007; Mariscal y Montaño, 2018; Montejano-Escamilla, 2015; Muñiz, Sánchez y García-López, 2015). ${ }^{3}$ No obstante, a pesar del surgimiento de subcentros terciarios más competitivos, el CTN se mantiene como pieza clave en la mayoría de las ciudades del mundo (Giuliano, Redfearn, Agarwal y He, 2012; Wrigley, 2013). Esto ocurre también en las grandes ciudades de México (Shearmur, Garrocho, Álvarez-Lobato y Chávez, 2015; Simmons, Garrocho y Kamikihara, 2016; Suárez-Lastra y Delgado-Campos, 2010).

En las ciudades latinoamericanas, incluidas las de México, el CTN tiene un doble rol: como símbolo que cohesiona a la población y como motor potente de la vida social y económica de las ciudades (Carrión, 2010). Es diferente de los demás centros de empleo de la ciudad: tiene características simbólicas y funcionales que lo hacen un actor estratégico del desarrollo integral urbano (Simmons, Garrocho, Kamikihara y Campos, 2018). En síntesis, para la ciudad latinoamericana es fundamental contar con un CTN que sea corazón simbólico y oferente competitivo de funciones centrales (gubernamentales, comerciales y servicios profesionales) y un motor orientado hacia el futuro, no un museo enfocado en el pasado (Carrión, 2010; Coulomb, 2018).

El CTN enfrenta desde hace décadas una feroz competencia con los centros emergentes modernos de empleo terciario (Garrocho y Campos, 2009). Estos nuevos centros terciarios (por lo general clústeres articulados por una gran plaza comercial) parecen estar ganándole el duelo en el sentido de que ahí se ubican las firmas más prestigiadas, los servicios de más alto orden; además, ahí se concentran las compras y se lleva a cabo el encuentro de los consumidores de mayores ingresos (Flores, Garrocho, Chávez y Álvarez-Lobato, 2013). También le sucede lo que a todo el sector de comercio al menudeo, enfrenta la intensa competencia de las ventas por internet (Ives, Cossick y Adams, 2019). ${ }^{4}$

El CTN no ha respondido con rapidez al nuevo entorno competitivo y está en un proceso de decadencia acumulativa (Lievanos y Villar, 2015). Si la tendencia se mantiene, puede perder su esencia: dejar de ser localización de funciones centrales (con potentes radios de influencia) y abandonar su lugar simbólico vibrante, para convertirse en un barrio histórico o museo temático sin visión de futuro (Carrión, 2010, p. 52).

El CTN no es homogéneo. En su interior se distinguen microespacios avanzados y competitivos (Gran Plaza Toluca), y otros pauperizados (las zonas aledañas a la Plaza de Armas o zócalo). Para que vuelva a ser motor de desarrollo

3 El CTN es equivalente al CBD. Ambos se localizan en la parte fundacional de la ciudad. Conforman el corazón de su vida política, social y comercial y son sede de los principales edificios públicos y de la zona de la ciudad con mayor valor simbólico en la conciencia cívica (Carrión, 2010; Goodall, 1987; Rice, 2009).

4 Se señala a Amazon como el principal enemigo del comercio minorista tradicional. En China, la empresa dominante es Alibaba. Esto se acentuó durante la pandemia del coronavirus de 2020 (https://www.nytimes.com/2020/07/09/business/stocks-after-coronavirus-investors.html). Mercado Libre registró en el segundo trimestre de 2020 ganancias netas que se dispararon en 245\% (https://www.dinero.com/empresas/articulo/mercado-libre-es-la-empresa-mas-valiosa-de-america-latina-en-2020/295269). 
socioeconómico, se requiere entender su evolución como zona de empleo en funciones centrales, en la escala microespacial. Esto permitiría desplegar estrategias público-privadas en sus tres coordenadas básicas: sector, lugar y tiempo.

\section{Marco analítico}

El ACPT se ha utilizado para examinar el cambio del empleo en ciertas áreas respecto al cambio del empleo en la región de la que forman parte. La literatura que explica el cambio y la participación (CP) es abundante (Niño, Arballo y Sández, 2003).

No obstante, el ACPT ha enfrentado fuertes opositores que argumentan que su contenido teórico es frágil, desde Richardson (1978), sensible al nivel de agregación de las actividades económicas y de las unidades espaciales, al periodo temporal que se considere, a limitaciones de tipo estadístico. Además, se objeta que no toma en consideración el papel de las relaciones espaciales entre unidades geográficas: como si operaran independientes unas de otras y no como sistema -el funcionamiento sistémico del CTN se demostró desde los años sesenta (Berry, 1964 y 2013)-. Los críticos señalaban que el ACPT era un método no espacial, aplicado al análisis de fenómenos espaciales, lo que implicaba una contradicción de fondo (Loveridge y Selting, 1998).

El ACPE es la respuesta a las numerosas críticas al ACPT (Nazara y Hewings, 2003). Con él, los ataques más importantes encontraron respuesta, de forma notable la exigencia justificada de incorporar al método la dimensión espacial (Ramajo y Márquez, 2008). Aportaciones pioneras en este sentido, son las de Patterson (1991), quien sitúa el ACPE en un marco territorial estocástico; Nazara y Hewings (2003 y 2004) integran la estructura espacial de la zona de estudio; Gallo y Kamarianakis (2011) fusionan las interacciones espacio-sectoriales; Ramajo y Márquez (2008) descomponen el cambio del empleo de una región en tres componentes sectoriales aditivos, modificados de forma espacial; y Zacommer y Mason (2011) ofrecen una alternativa para incluir la estructura espacial.

En la actualidad, el ACPE tiene un lugar sólido en la literatura especializada. En años recientes ha registrado avances adicionales y ha mostrado su utilidad para analizar la dinámica del empleo en Grecia (Psycharis, Kallioras y Pantazis, 2018), Europa (Kivi, 2019), Corea del Sur (Mo, Lee, Lee y Park, 2020) y México (Flores, Solís y Álvarez-Aros, 2020; Rendón, Andrés y Mejía, 2019; Valdez, 2018), pero también para examinar otros temas relacionados: productividad regional en España y Portugal (Melchor-Ferrer, 2020), demografía de las firmas en Italia (Piacentino, Espa, Filipponi y Giuliani, 2017) y trayectoria económica regional en España (Albertos, 2019).

Aquí se utiliza la metodología de Ramajo y Márquez (2008), ya que ofrece una formulación general del ACPE que integra en la misma estructura operativa el ACPT y considera de manera explícita que los cambios del empleo y sus causas son dependientes en términos espaciales. Para el presente trabajo, esto significa que el desempeño en materia de empleo de cada microespacio que integra el CTN influye en y está influido por el desempeño del resto, pero 
con más fuerza por los microespacios vecinos, efecto espacial reconocido por Tobler (1970).

\section{Metodología 5}

Área de estudio

Garrocho y Flores (2009) han delimitado el CTN del AMT de forma espacial a partir de la intensidad de flujos peatonales. Aquí se retoma esa delimitación que también han utilizado mucho el gobierno municipal de Toluca y la asociación de comerciantes del CTN. La superficie del CTN suma 4.7 kilómetros cuadrados $\left(\mathrm{km}^{2}\right)$. Se divide en 47 microespacios hexagonales (regulares) de diez hectáreas cada uno, con una apotema cercana a 400 metros: la distancia promedio que recorren los peatones en el CTN (Garrocho y Flores, 2009). En esta zona vive una numerosa población de 65 años o más (Ramírez-Sánchez, 2020). La definición de los microespacios hexagonales se realizó de forma automatizada con la herramienta de teselación de Christaller ${ }^{\circledR}$ (Chávez-Soto y Garrocho, 2018).

Métodos

Premisas básicas del ACPE aplicado en este trabajo:

1. El CTN se divide en microespacios hexagonales $j$, con el fin de tener unidades homogéneas comparables -recomendación de Fuenzalida, Buzai, Moreno Jiménez y García de León (2015)-. Como demuestra la teoría del lugar central, el hexágono es la figura más adecuada para cubrir un territorio económico especializado en actividades terciarias (Garrocho, 2003).

2. Todos los microespacios $j$ son parte de una zona o región referencial $k$ (el CTN) o k' (el AMT, si se analiza el CTN como unidad geográfica). Los microespacios forman zonas vecinales con los microespacios vecinos $V$.

3. Se consideran vecinos los microespacios que comparten cualquier frontera, el llamado criterio de la reina (Garrocho y Campos, 2013). Esto se justifica por la sensibilidad de los flujos de compradores en $k$ (el CTN) ante variaciones en la distancia (Garrocho y Flores, 2009; Jones y Simmons, 1990).

4. Los microespacios $j$ interactúan entre sí, de manera directa e indirecta (a través de las zonas vecinales $V$, del CTN $k$ o del AMT $k^{\prime}$ ). Conforman un sistema complejo que funciona de modo simultáneo a diversas escalas territoriales. En este trabajo se consideran cuatro escalas interrelacionadas: metropolitana $k^{\prime}$, CTN $k$, vecinal $V$ y microespacial $j$.

5. Las unidades geográficas $k^{\prime}, k, V, j$ transmiten impulsos positivos o negativos entre sí que influyen en el cambio del empleo en todo el sistema en todas las escalas al mismo tiempo.

5 En esta sección se presenta una síntesis del razonamiento numérico del ACPE. Explicaciones matemáticas detalladas pueden verse en Ramajo y Márquez (2008), Valdez (2018) y Rendón, Andrés y Mejía (2019). 
6. La intensidad de las relaciones entre los microespacios $j$ varían en función de su vecindad.

7. Las interrelaciones espacio-sectoriales en el sistema de microespacios $j$ en las escalas $V$ y $k$ se representan mediante una matriz geográfica de pesos espaciales $W_{j k}$ (Ramajo y Márquez, 2008; Rendón, Andrés y Mejía, 2019; Valdez, 2018). Esta matriz puede calcularse de diversas maneras. Lo importante es que tenga una vinculación fuerte con las variables espaciales que afectan el cambio del empleo en la zona de estudio. Para el CTN son fundamentales los flujos de compradores: su variación e impacto en el espacio es notable (Garrocho y Flores, 2009).

8. La influencia de $k^{\prime}, k$ sobre $j$ es indirecta: a través de $k \circ V$, según la escala del análisis. La influencia de $V$ sobre $j$ es directa: por vecindad.

9. El cambio del empleo se mide en términos de velocidad (tasa, porcentaje) y volumen (empleos).

10. Los resultados del ACPT y del ACPE son valiosos por su orden de magnitud. Facilitan la formulación de explicaciones generales, preguntas e hipótesis. Orientan con alta precisión espacial y sectorial estudios cualitativos complementarios. Ofrecen un marco para cohesionar estrategias y acciones de política pública y privada, en espacio, sector y tiempo.

Secuencia de los cálculos del ACPE aplicado en este trabajo:

Los insumos básicos del ACPE son los datos del empleo espacialmente modificados. Esto es, considerando la localización del empleo vía la matriz de pesos espaciales: $W_{j k}$. Por tanto, se requieren tres estimaciones preliminares (véase figura 1).

a) Tasa de crecimiento del empleo en el sector $i$ en el microespacio $j$ respecto al empleo total en $k$ o respecto a sus vecinos $V$ según el criterio de vecindad (ecuación 1):

$$
X_{i z}^{V^{*}}=\sum_{z \in V} W_{i z} X_{i z}
$$

Donde:

$X i j$ es el empleo en el $i$-ésimo sector y en el $j$-ésimo microespacio.

$g=$ tasa de crecimiento del empleo en el CTN.

$g_{i}=$ tasa de crecimiento del empleo del sector $i$ en el CTN.

$g_{i j}=$ tasa de crecimiento del empleo del sector $i$ en el microespacio $j$.

$\mathrm{W}_{\mathrm{iz}}=$ matriz de pesos espaciales.

$S=$ sectores del empleo.

$k=$ región referencial.

$z=$ vecinos de la unidad geográfica local $j$.

$E C=$ efecto del CTN.

EMS = efecto de la mezcla sectorial.

ERNE = efecto regional neto espacial.

$E D E$ = efecto diferencial espacial.

$E C L=$ efecto de la competitividad microespacial.

$\mathrm{CNE}=$ cambio neto espacial. 
Figura 1. Algoritmo: cálculo del cambio y participación espacial

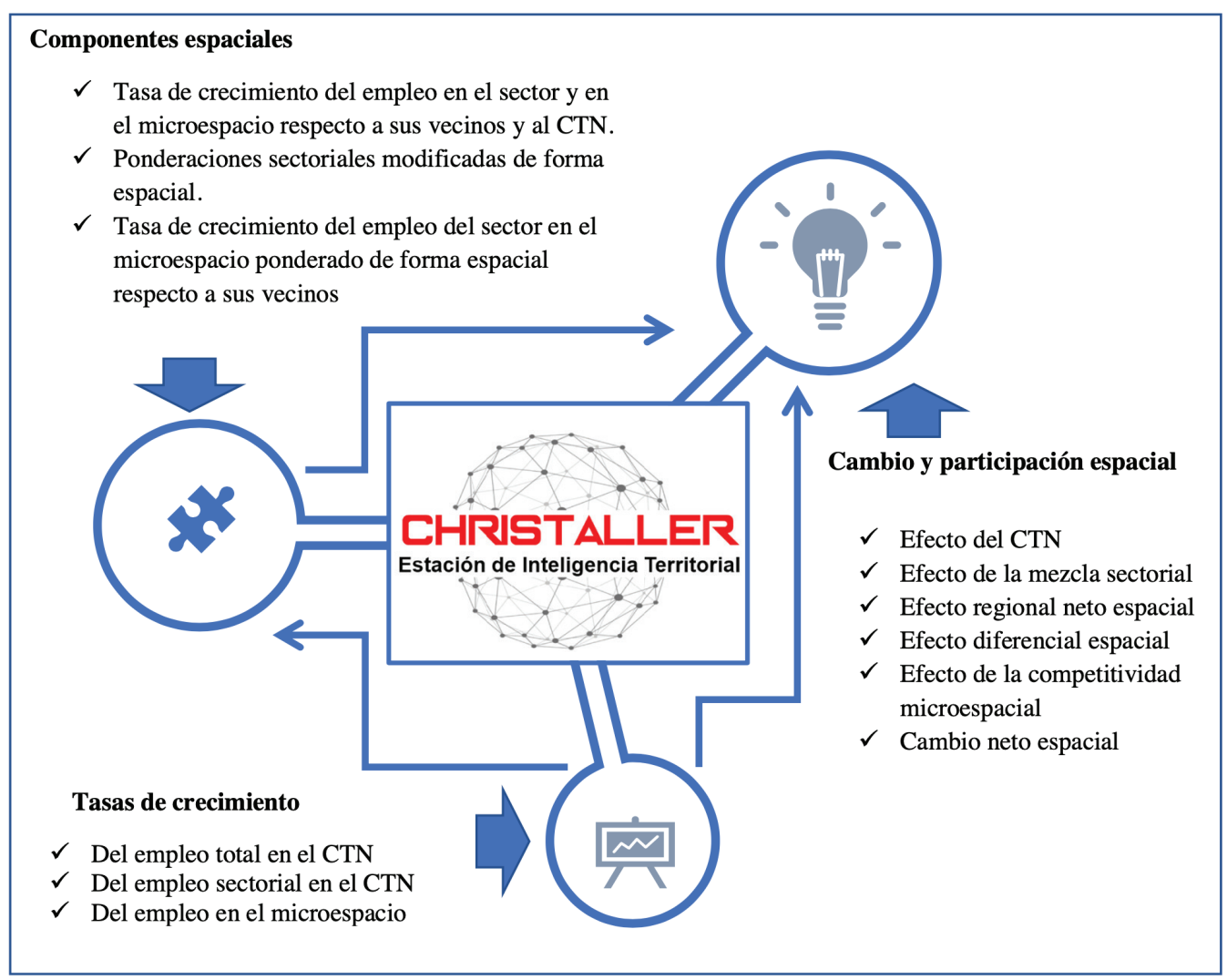

Fuente: elaboración propia.

b) Ponderaciones sectoriales, modificadas de forma espacial (ecuación 2):

$$
\frac{X_{i}^{v *}}{X^{*}}=\frac{\sum_{j}^{k} X_{i j}^{v *}}{\sum_{i}^{S} \sum_{j}^{k} X_{i j}^{v *}}
$$

c) Tasa de crecimiento del empleo en el sector $i$ en $j$ ponderada de forma espacial, respecto a sus vecinos $V$ (ecuación 3 ):

$$
X_{i j}^{v * *}=X_{j} \frac{X_{i}^{v *}}{X^{*}}
$$

Los cambios en el empleo de cada microespacio $j$ en cada sector $i$, durante un cierto periodo $(t, t+1)$, se deben a tres efectos principales con causas distintas: efecto de la zona referencial (efecto del CTN), efecto de la mezcla sectorial y efecto de la competitividad microespacial. 
d) Efecto de la zona referencial ( $E C=$ ecuación 4). Es el impulso o lastre de la zona referencial $V, k$, sobre los microespacios $j$ que la integran. Hay que recordar que la influencia de $k$ sobre $j$ es indirecta: a través de $V$. Si la zona referencial $(V, k)$ es dinámica como generadora de empleo, es probable que sus microespacios $j$ se beneficien, y viceversa:

$$
E C=X_{i j} g=X_{i j}\left(\frac{\sum_{i}^{S} \sum_{j}^{k}\left(X_{i j}^{t+1}-X_{i j}\right)}{\sum_{i}^{S} X_{i j}}\right)
$$

e) Efecto de la mezcla sectorial ( $E M=$ ecuación 5). Es el impulso o lastre que se deriva de la especialización sectorial de los microespacios $j$ que integran la zona referencial $V, k$. Si se especializan en sectores dinámicos de la zona referencial, será más probable que los microespacios creen empleos. Si se especializan en sectores lentos o decrecientes de $V, k$, ocurrirá lo contrario:

$$
\mathrm{EMS}=X_{i j}\left(g_{i}-g\right)=X_{i j}\left(\left(\frac{\sum_{j}^{k}\left(X_{i j}^{t+1}-X_{i j}\right)}{\sum_{j}^{k}\left(X_{i j}\right)}\right)-\left(\frac{\sum_{i}^{S} \sum_{j}^{k}\left(X_{i j}^{t+1}-X_{i j}\right)}{\sum_{i}^{S} X_{i j}}\right)\right) \quad 5
$$

f) Efecto de la competitividad microespacial ( $E C L=$ ecuación 6). Cuantifica el empleo que se deriva de la competitividad de cada microespacio $j$ que integra la zona referencial $V, k$. Resulta de la interacción de dos causas subsidiarias que operan de manera diferenciada en el territorio: más intensamente en la escala vecinal $V$ y de manera indirecta en la escala del CTN $k$, y también del AMT $k^{\prime}$ (a través de $k$ ). Estas causas subsidiarias son el efecto regional neto espacial (ERNE) y el efecto diferencial espacial (EDE). El ERNE compara la tasa de crecimiento del empleo del sector $i$ en el microespacio $j$, operando en un sistema de microespacios interrelacionados en el territorio $V, k$. Puede entenderse como una hipótesis de cambio tendencial del empleo en cada sector $i$ en $j$, derivado del cambio del empleo en cada sector $i$ en la escala $V$, pero también, de manera indirecta, en $k$. Es decir: es el cambio del empleo $i$ en $j$ si la estructura sectorial de $j$ fuera igual a la de sus vecinos $V$ y muy parecida a la del CTN $k$ (ecuaciones 6, 7 y 8 ).

$$
\mathrm{ERNE}=X_{i j}^{v * *}\left(g_{i j}-g_{i}\right)
$$

Por su parte, el EDE considera la estructura espacial de $V$ (y de manera indirecta la de $k$ ) y su aporte al empleo del sector $i$ en $j$ (ecuación 7 ). Éste es un primer indicador de las ventajas o desventajas competitivas de $j$ respecto a $V y$, de forma indirecta, respecto a $k$.

$$
\mathrm{EDE}=\left(X_{i j}-X_{i j}^{v * *}\right)\left(g_{i j}-g_{i}\right)
$$




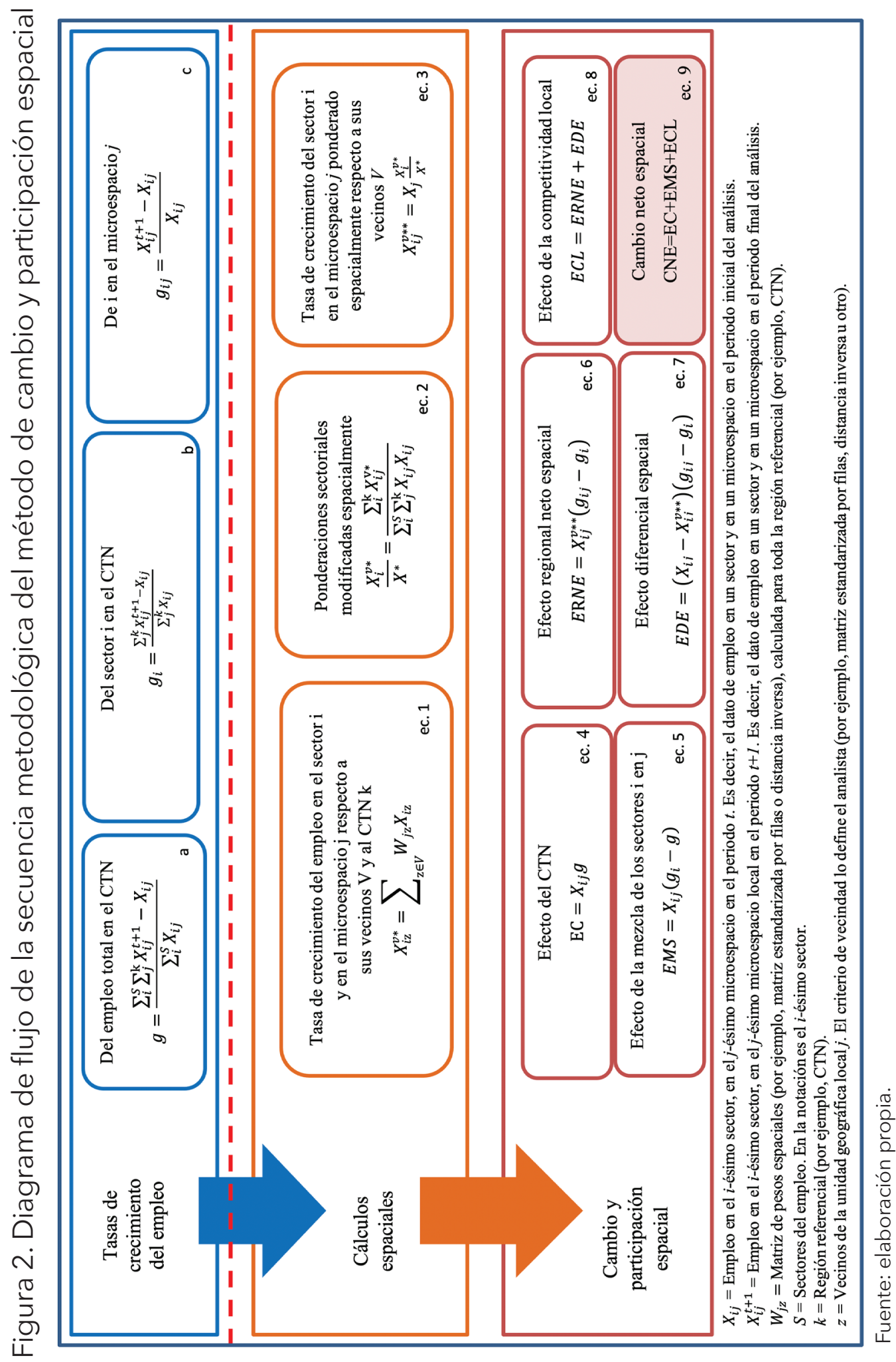


La suma del ERNE y el EDE es el efecto de la competitividad microespacial $(E C L=$ ecuación 8).

$$
E C L=E R N E+E D E
$$

g) Los efectos CTN, MS y CL pueden tener comportamientos disímiles (positivos o negativos). Su sumatoria produce el cambio neto espacial total (CNE) del empleo en cada microespacio $j$ (ecuación 9):

$$
\mathrm{CNE}=\mathrm{EC}+\mathrm{EMS}+\mathrm{ECL}
$$

La secuencia de los cálculos se presenta paso a paso en la figura 2.

Fuentes de información y software utilizado

Los cálculos se realizaron con la herramienta spatial shift-share ${ }^{6}$ de la Estación de Inteligencia Territorial Christaller ${ }^{\circledR}$ (Chávez-Soto y Garrocho, 2018), en su versión 1.2 para Windows. Christaller ${ }^{\circledR}$ opera de manera transparente en los sistemas de información geográfica (SIG), siguiendo el concepto de cyber geographic information science and systems (CyberGIS) (Anselin, 2013).

Los datos de entrada son el empleo georreferenciado en la zona de estudio para dos momentos en el tiempo $(t$ y $t+1)$ de los microespacios $j$ que conforman la zona referencial $k$ (el CTN), $k^{\prime}$ (el AMT). La principal fuente de información es el Directorio Estadístico Nacional de Unidades Económicas (DENUE) (Instituto Nacional de Estadística y Geografía [INEGI], 2019). Los datos completos de empleo en el CTN en $2010(t)$ y $2018(t+1)$ se reportan agrupados en 17 sectores (véase tabla 1).

Por motivos de confidencialidad, el DENUE no detalla el empleo a escala de unidad económica ni por microespacio $j$. Como dato proxy del empleo, se estimó el empleo medio en cada microespacio $j$. El método ya ha sido probado y se detalla en Shearmur, Garrocho, Álvarez-Lobato y Chávez (2015). ${ }^{7}$ La matriz estandarizada de pesos espaciales también se estimó con Christaller ${ }^{\oplus}$.

6 Para tener acceso a las herramientas de spatial shift-share y teselación de la estación Christaller ${ }^{\circledR}$, consúltese la siguiente página web http://www.christaller.org.mx/

7 El DENUE reporta rangos de empleo por unidad económica. En varios trabajos recientes los autores han tomado el punto medio de cada rango como dato de empleo. El rango superior (251 empleo o más) lo han igualado a 350. Esto es producto de los análisis estadísticos de una muestra de unidades económicas: aunque hay variaciones por unidad económica, las diferencias se compensan en los grandes agregados, lo que es suficiente para los objetivos. Este mismo método se ha utilizado en Campos-Alanís, Ramírez-Sánchez y Garrocho (2020), Rojas, Mejía y Díaz (2021), Shearmur et al. (2015) y Vilchis, Garrocho y Chávez (2021). 


\section{Tabla 1. Sectores económicos presentes en el centro tradicional de negocios de Toluca}

\begin{tabular}{|c|c|}
\hline $\begin{array}{c}\text { Clave del } \\
\text { sector }\end{array}$ & $\begin{array}{c}\text { Sector: descripción para el área metropolitana de Toluca } \\
\text { y su centro tradicional de negocios }\end{array}$ \\
\hline 21 & Minería \\
\hline 22 & $\begin{array}{c}\text { Generación, transmisión, distribución y comercialización } \\
\text { de energía eléctrica, suministro de agua y de gas natural por ductos } \\
\text { al consumidor final: comisión de agua potable de cada municipio, Petróleos } \\
\text { Mexicanos, Comisión Federal de Electricidad }\end{array}$ \\
\hline 23 & Construcción \\
\hline 31 & $\begin{array}{l}\text { Industria alimentaria: todo tipo, refrescos, alcoholes, agua, dulces, } \\
\text { telas, ropa, cuero, jarcerías }\end{array}$ \\
\hline 32 & $\begin{array}{l}\text { Industria de madera: imprentas en papel, en gran formato, espectaculares, } \\
\text { invitaciones }\end{array}$ \\
\hline 33 & $\begin{array}{l}\text { Industria metálica básica: fundidoras, fabricación de acero, ferroaleaciones, } \\
\text { herrerías, Maquinaria y equipo, autos, autopartes, motores, talleres oftálmicos }\end{array}$ \\
\hline 43 & $\begin{array}{c}\text { Comercio al por mayor: distribuidoras de huevo, pan, pasteles, } \\
\text { embutidos, telas, calzado, ropa, perfumería, cosméticos, envases } \\
\text { de cartón, ferreterías, pintura, mobiliario, equipo de oficina, } \\
\text { cómputo, intermediación }\end{array}$ \\
\hline 46 & Comercio al por menor: ropa, calzado, papelerías, joyerías, ferreterías, cómputo \\
\hline 52 & $\begin{array}{l}\text { Servicios financieros y de seguros: bancos, seguros, préstamos, casas } \\
\text { de empeño, fondos de pensiones, autofinanciamiento }\end{array}$ \\
\hline 53 & $\begin{array}{c}\text { Servicios inmobiliarios y de alquiler de bienes muebles e intangibles: } \\
\text { casas, oficinas, vehículos, maquinaria }\end{array}$ \\
\hline 54 & $\begin{array}{l}\text { Servicios profesionales, científicos y técnicos: despachos de profesionistas, } \\
\text { notarías, científicos, veterinarios }\end{array}$ \\
\hline 56 & $\begin{array}{c}\text { Servicios de apoyo a los negocios y manejo de residuos, y servicios } \\
\text { de remediación. Recolección y manejo de residuos de salud, asesoría } \\
\text { cuyo insumo es conocimiento y experiencia del personal, } \\
\text { agencias de empleo, fotocopiado, apoyo secretarial, seguridad, limpieza }\end{array}$ \\
\hline 61 & $\begin{array}{l}\text { Servicios educativos: públicos y privados de todos los niveles, } \\
\text { arte, idiomas, cómputo, conservatorios }\end{array}$ \\
\hline 62 & $\begin{array}{c}\text { Servicios de salud y de asistencia social: públicos y privados, consultorios, } \\
\text { dentistas, laboratorios clínicos, trabajo social }\end{array}$ \\
\hline 71 & $\begin{array}{l}\text { Servicios de esparcimiento, culturales, deportivos y otros servicios recreativos: } \\
\text { deportes profesionales, museos, jardines botánicos, parques, } \\
\text { grupos musicales, festivales }\end{array}$ \\
\hline 72 & $\begin{array}{l}\text { Servicios de alojamiento temporal y de preparación de alimentos y bebidas: } \\
\text { hoteles, centros nocturnos, bares, restaurantes, cafeterías, hamburguesas }\end{array}$ \\
\hline 81 & $\begin{array}{c}\text { Otros servicios, excepto actividades gubernamentales: estacionamientos } \\
\text { y pensiones, asociaciones públicas y privadas }\end{array}$ \\
\hline
\end{tabular}




\section{Resultados}

Dinámica del empleo en el CTN

en el contexto de la ciudad: primer acercamiento

El CTN registró en el periodo de estudio una ganancia de poco más de 7 mil empleos (véase tabla 2). Pasó de cerca de 40 mil en 2010 a más de 47 mil en 2018: un crecimiento de $12 \%$ (redondeando cifras). El crecimiento neto total del empleo en el CTN es lento, si lo comparamos con el de toda la ciudad en los mismos sectores que operan en el CTN: $21.6 \%$.

Sin embargo, la comparación no es justa: el CTN tiene muchas menos actividades económicas en cada sector que la ciudad en su conjunto, sobre todo en los sectores de tipo manufacturero. Además, la superficie del CTN llega a 4.7 km², mientras que la ciudad tiene un área de $28.7 \mathrm{mil} \mathrm{km}^{2}$. La economía urbana indica que la mayor ventaja del CTN es su accesibilidad. Su principal desventaja, el costo elevado del suelo (precio, alquileres) (O’Sullivan, 2007). Por lo tanto, para lograr un mejor enfoque del cambio del empleo en el CTN, comparado con el de la ciudad, se deben priorizar los sectores en los que el CTN ha sido dominante y privilegiar la velocidad del crecimiento sobre el aumento de volumen.

El principal sector del CTN ha sido siempre el comercio minorista, que sigue siendo fuerte. ${ }^{8}$ En el estudio, 2010-2018, el CTN incrementó su empleo 42.5\% (5.2 mil empleos), contra un aumento de $12.2 \%$ en toda la ciudad. En servicios financieros y de seguros (sobre todo bancos), se duplicó su empleo: creció 108.8\% (534 empleos). En la ciudad, en cambio, creció el empleo 58.7\%. En servicios de esparcimiento, culturales y deportivos, el CTN registró un desempeño muy superior al de la ciudad. Mientras éste superó el doble de su empleo, la ciudad lo aumentó $31 \%$. En cuanto a estos servicios, vale mencionar que en el CTN se localizan el estadio, el museo y la tienda del equipo profesional de fútbol de la ciudad (que participa en el máximo circuito). También se han realizado importantes inversiones en el jardín botánico, los museos y los parques, y se llevan a cabo numerosos festivales artísticos.

En el resto de los sectores, el desempeño del CTN como generador de empleo no es tan positivo. El sector de servicios inmobiliarios tuvo una velocidad de crecimiento muy similar al de la ciudad: alrededor de $15.5 \%$. Resulta más preocupante la pérdida de empleos en sectores estratégicos. En servicios profesionales, científicos y técnicos, sobre todo en despachos de profesionistas, el empleo decayó 8.4\%. Esto confirma que el CTN ya no ofrece la localización de más prestigio para los profesionales liberales (Garrocho y Campos, 2009): el prestigio locacional se ha movido a otros puntos de la ciudad (por ejemplo, Metepec), donde el empleo en estos servicios creció $11.6 \%$.

8 Hasta aquí se ha asumido que los empleos y las firmas del CTN y del resto de la ciudad son de similar calidad. No se tienen datos estadísticos al respecto, pero hay evidencia de que su calidad en el CTN es inferior (Garrocho y Campos, 2009). Por ejemplo, ninguna de las diez marcas de moda más buscadas en México se localiza en el CTN: Zara, Nike, Vans, Skechers, Bershka, Puma, Forever 21, L'Oreal, Andrea, Price Shoes. https://marketing4ecommerce.mx/top-10-las-marcas-moda-mas-buscadas-enmexico/ 


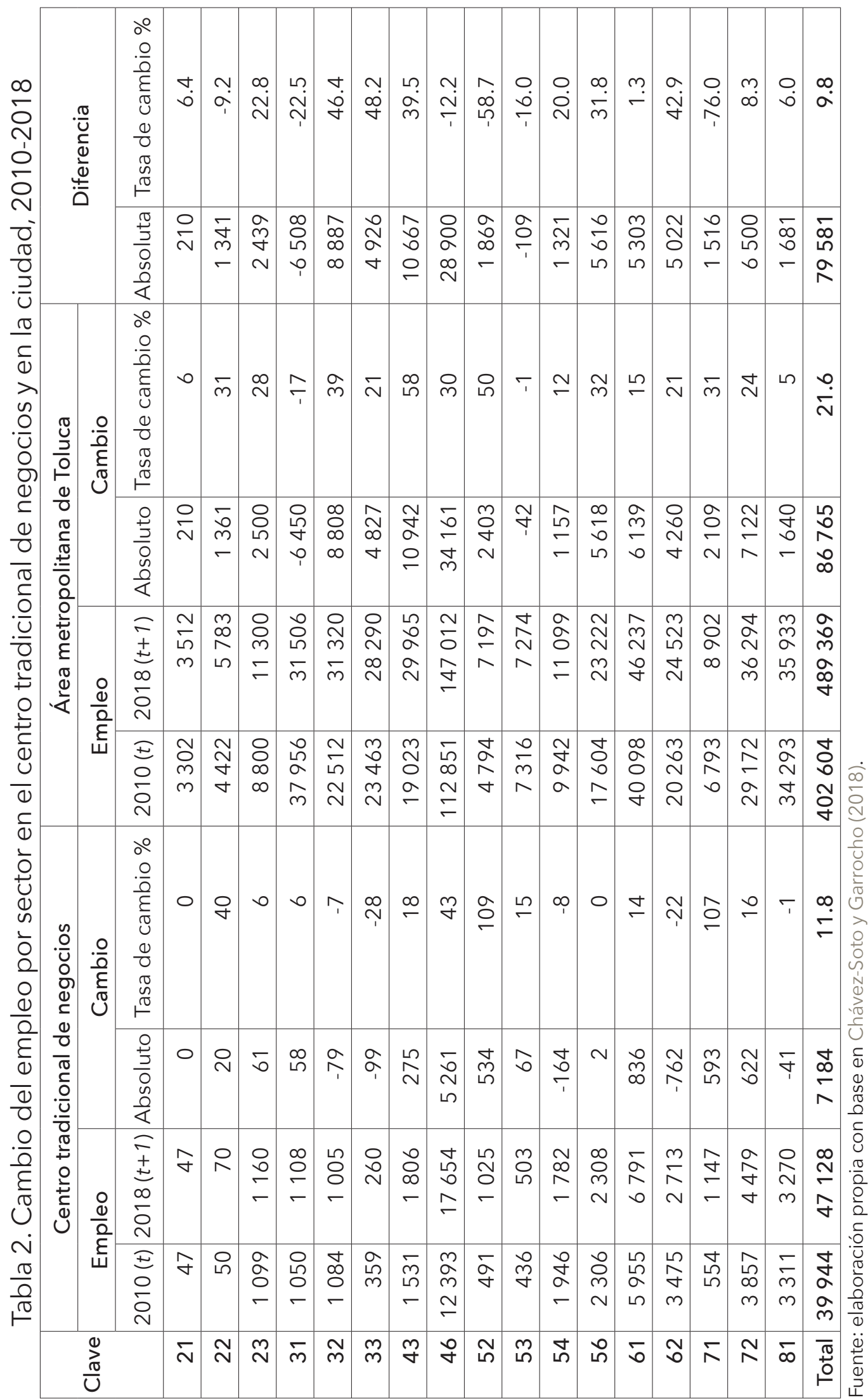


Algo similar sucede con los servicios de salud. Se entiende que los nuevos hospitales se localicen fuera del CTN por el costo del suelo. No obstante, es notable la emigración de consultorios médicos, dentales, laboratorios clínicos y otros servicios de salud privados. También se ha perdido terreno en los servicios educativos, que siempre fueron dominados por el CTN, localización prioritaria de escuelas públicas, privadas, de arte, idiomas y cómputo. El CTN y la ciudad aumentan su empleo en este sector de manera similar (15\%). En servicios de alojamiento temporal y de preparación de alimentos y bebidas (hoteles, discotecas, bares, restaurantes, cafeterías), el CTN ha tenido un repunte y creció su empleo $16.1 \%$, pero aún por debajo de lo que aumentó en la ciudad (24.4\%).

¿Cómo se explican las diferencias de ritmo de creación de empleo entre el CTN y la ciudad?

Dado que se trata de comparar sólo dos unidades geográficas - el CTN y toda la ciudad (el AMT, que es la zona referencial)-, el ACPT es suficiente para identificar las causas de los cambios diferenciados de creación de empleos. El eje del análisis será el efecto de la competitividad microespacial, porque es el que resultará más útil para interpretar, más tarde, los resultados del ACPE en los microespacios del CTN.

Como se esperaba, el ACPT confirma que el sector predominante en el CTN es el comercio minorista. Lo más importante emerge al analizar las causas del cambio en el empleo. De los 5261 empleos que creó el CTN en este sector, 46.1\% se debieron a la competitividad microespacial, $42.4 \%$ al efecto metropolitano y $11.6 \%$ al efecto de la mezcla sectorial (véase tabla 3). Esto significa que el crecimiento del empleo en el comercio minorista del CTN no se fundamenta en dicha competitividad, sino que depende en gran medida del impulso que le da la ciudad (la inercia metropolitana). Además, la oferta de comercios y servicios que ofrece el CTN (su mezcla sectorial) no coincide con las actividades minoristas más dinámicas de la ciudad, que se organizan en centros emergentes articulados por plazas comerciales planificadas (Garrocho y Campos, 2009). Para otros sectores, como los servicios de esparcimiento, culturales y deportivos, el CTN es muy competitivo: $89 \%$ del aumento en el empleo se debe a su competitividad microespacial. También lo es servicios financieros y de seguros, ya que $81.3 \%$ de los nuevos empleos de este sector se deben a las ventajas competitivas que ofrece el CTN (es sede de los gobiernos estatal, municipal, del Poder Legislativo y de un gran volumen de comercios).

Los escenarios son diferentes para otros sectores. Aunque el empleo en servicios educativos creció en el CTN (836 nuevos empleos), la situación es preocupante. El CTN no aprovechó el impulso de la ciudad, que le debería haber aportado 1071 empleos, ya que fueron contrarrestados por su pobre mezcla sectorial (-141 empleos: se especializó en actividades educativas de crecimiento lento) y por sus desventajas competitivas (-94 empleos). En servicios de alojamiento y preparación de alimentos y bebidas, la situación es similar: aumentó en 622 empleos, pero otra vez registra desventajas competitivas (-98 empleos). La catástrofe para el CTN se registró en las actividades relacionadas con con- 


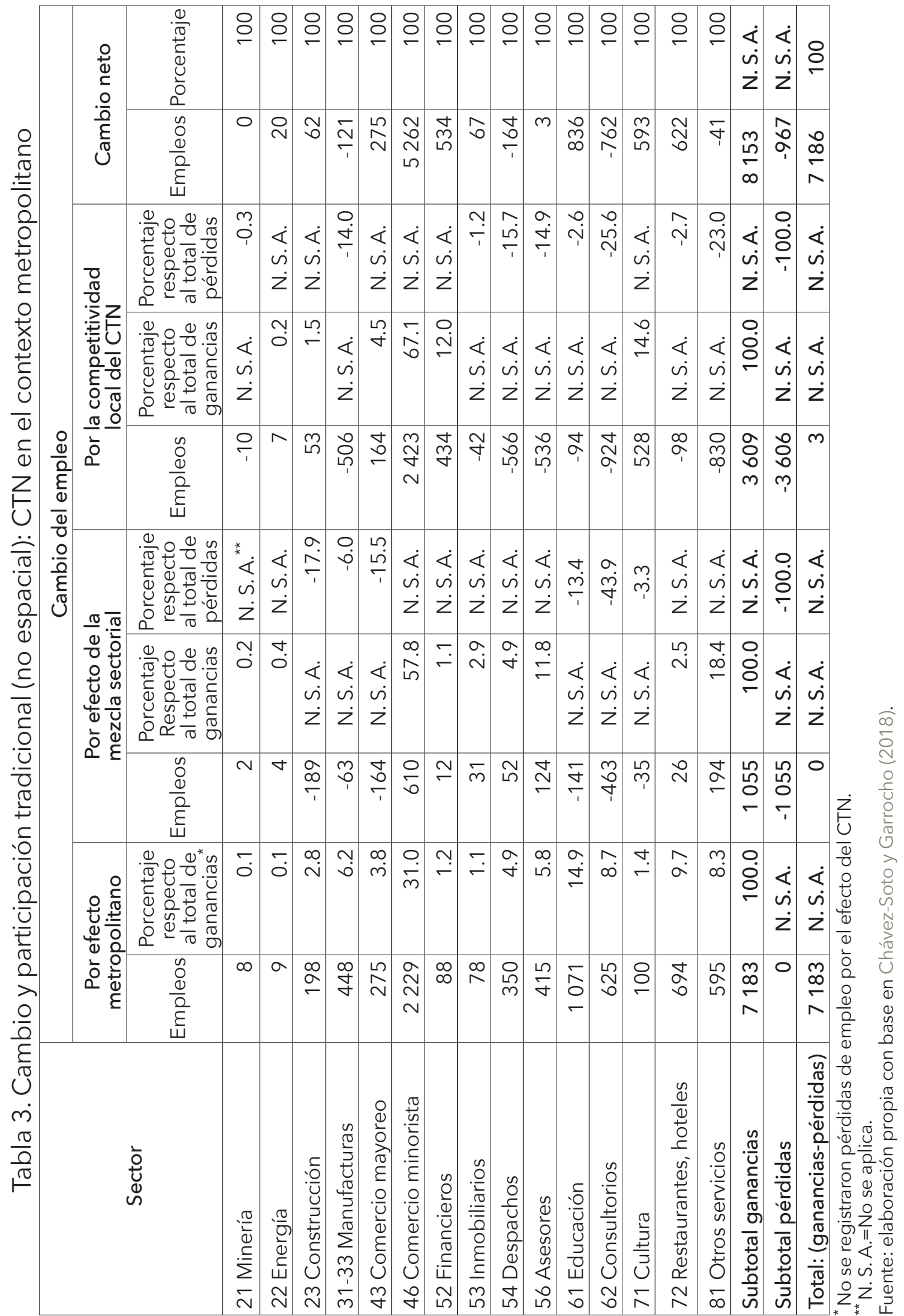


sultorios médicos y despachos de profesionales (incluidos los de asesores de negocios), sectores a los cuales la ciudad dio un impulso positivo muy importante (1 390 empleos), aunque se evaporó porque la oferta del CTN se concentraba en las actividades rezagadas en la ciudad (mezcla sectorial: - 463 empleos) y, en particular, por sus considerables desventajas competitivas para consultorios y despachos (-2 026 empleos). El antiguo prestigio del CTN como localización de actividades profesionales liberales ya no existe.

Hasta aquí se ha considerado el CTN como una unidad geográfica homogénea, lo cual es válido para tener un primer acercamiento a la dinámica del empleo en la zona. Sin embargo, sabemos que es muy heterogéneo en su interior, que los flujos de compradores son muy diferenciados y que un error de unas decenas de metros en la localización de un negocio puede marcar la diferencia entre el éxito económico y la quiebra (Garrocho, 2005; Garrocho y Flores, 2009; Jones y Simmons, 1990). Por lo tanto, para elaborar estrategias de reactivación del empleo en el CTN es necesario explorar su espacio interior. Es decir, examinar sus microespacios.

Dinámica del empleo en el espacio interior del CTN

Como se asentó antes, el CTN está integrado por microespacios que interactúan entre sí como sistema. La intensidad de sus interacciones varía en función de su vecindad (véase marco de referencia). La estrategia de análisis que se siguió en esta sección fue aplicar el ACPE para considerar la importancia de la dimensión geográfica en el cambio del empleo al interior del CTN. Para lograr esto, se dividió el CTN en microespacios hexagonales regulares. La justificación de su forma y extensión se presentó en la metodología.

Por consiguiente, en este estudio del ACPE la zona referencial de influencia directa en los microespacios son sus vecinos $V$, pero de manera indirecta también influye el CTN $k$ (véase metodología). Se calculan los resultados numéricos para todos los sectores presentes en el CTN a escala de microespacio. Por la extensión de este texto, no es posible presentarlos todos (son 17 sectores para cada uno de los 47 microespacios). Se concentra el análisis microespacial en dos sectores estratégicos para cualquier CTN, por su carácter de funciones centrales (Carrión, 2010): comercio al menudeo (sector 46) y servicios de profesionales (la suma de los sectores $54,56,62$ ). Se analizan sólo los principales microespacios ganadores y perdedores de empleo.

¿Cómo se explican las diferencias de velocidad y volumen de creación de empleo al interior del CTN?

Aquí se examina el desempeño de los 47 microespacios de éste como creadores de empleo. Dado que la localización de cada uno afecta bastante su desempeño (Garrocho, 2005), se aplica el cambio y participación espacial, lo cual permitirá aislar y cuantificar las causas de los cambios del empleo al interior del CTN. 
Comercio al menudeo (sector 46$)^{9}$

El desempeño del empleo al interior del CTN es heterogéneo. El cambio neto del empleo registra ganancias importantes en seis de los 47 microespacios (véase figura 3). Los datos completos se presentan en la tabla 3. ¿Cuáles son los microespacios claves? ¿Hay alguno que sea ganador estratégico para el CTN? ¿Cuáles microespacios son los grandes perdedores?

El microespacio líder en ganancia de empleos es AW-38, que incluye el cruce de las calles Hidalgo y Juárez, la intersección más importante del CTN en términos de flujos peatonales. Este cruce, corazón del CTN, alcanza una intensidad de cerca de siete mil peatones por hora los sábados al mediodía (Garrocho y Flores, 2009). Lo interesante es que en este microespacio el empleo sigue creciendo gracias a nuevas estrategias de intensidad de ocupación del suelo: pequeñas plazas comerciales planificadas de varios niveles (por ejemplo, Plaza del Sol), mayor densidad de empleo y localización de negocios que emplean más trabajadores.

Todos los efectos del microespacio AW-38 fueron importantes y positivos. La dinámica del CTN impulsó la creación de 408 empleos: efectos CTN y vecinal (efecto CTN-V). La mezcla sectorial del microespacio fue muy favorable y produjo 667 empleos y por efecto de la competitividad microespacial creó 553 empleos. Además, las dos causas subsidiarias de la competitividad microespacial también contribuyeron al aumento del empleo, aunque si la estructura del efecto regional neto espacial (ERNE) -que cuantifica el empleo impulsado en AW-38- fuera similar a la de sus vecinos, éste sería bajo. El efecto de distribución espacial (EDE), que cuantifica el cambio en el empleo debido a sus ventajas competitivas sobre sus vecinos, es muy alto (553). ${ }^{10}$ Es decir, el microespacio AW-38 es de manera positiva distinto a sus vecinos, lo que le permitió elevar su velocidad y volumen de empleo. Al final, el cambio neto del empleo en este microespacio fue de 1628 empleos. Este hallazgo significa que 30.9\% de los empleos creados en el CTN en el comercio minorista ocurrieron en el microespacio AW-38. Ahí también se localizó $22.3 \%$ de los empleos que creó el CTN en sus 17 sectores, lo cual es notable para un microespacio de diez hectáreas que, sin duda, es estratégico para el CTN.

El siguiente microespacio con el mejor desempeño en creación de empleos fue el AY-38. No colinda con el microespacio AW-38 y está rodeado por microespacios perdedores de empleo, salvo dos (véase figura 3). AY-38 no recibe impulso de la dinámica del CTN (30 empleos por efecto CTN-V), lo que implica que se especializa en actividades diferentes a las más dinámicas del CTN y de sus vecinos. En efecto, este microespacio integra un clúster especializado en partes electrónicas y audio, el cual incluye los microespacios AY-39 y AZ-39, que registraron ganancias modestas de empleo. La mezcla sectorial de AY-38

9 Se estimaron las causas del cambio del empleo para los 17 sectores económicos que operan en el CTN. Por razones de extensión de este texto, sólo se presentan en detalle dos sectores claves: comercio minorista y servicios de profesionales. Los resultados para los demás sectores pueden solicitarse a tchavez@cmq.edu.mx

10 Develar en detalle por qué este microespacio es tan competitivo para el comercio minorista (las causas de las causas), está fuera de los alcances de este trabajo y será objeto de futuras investigaciones. 


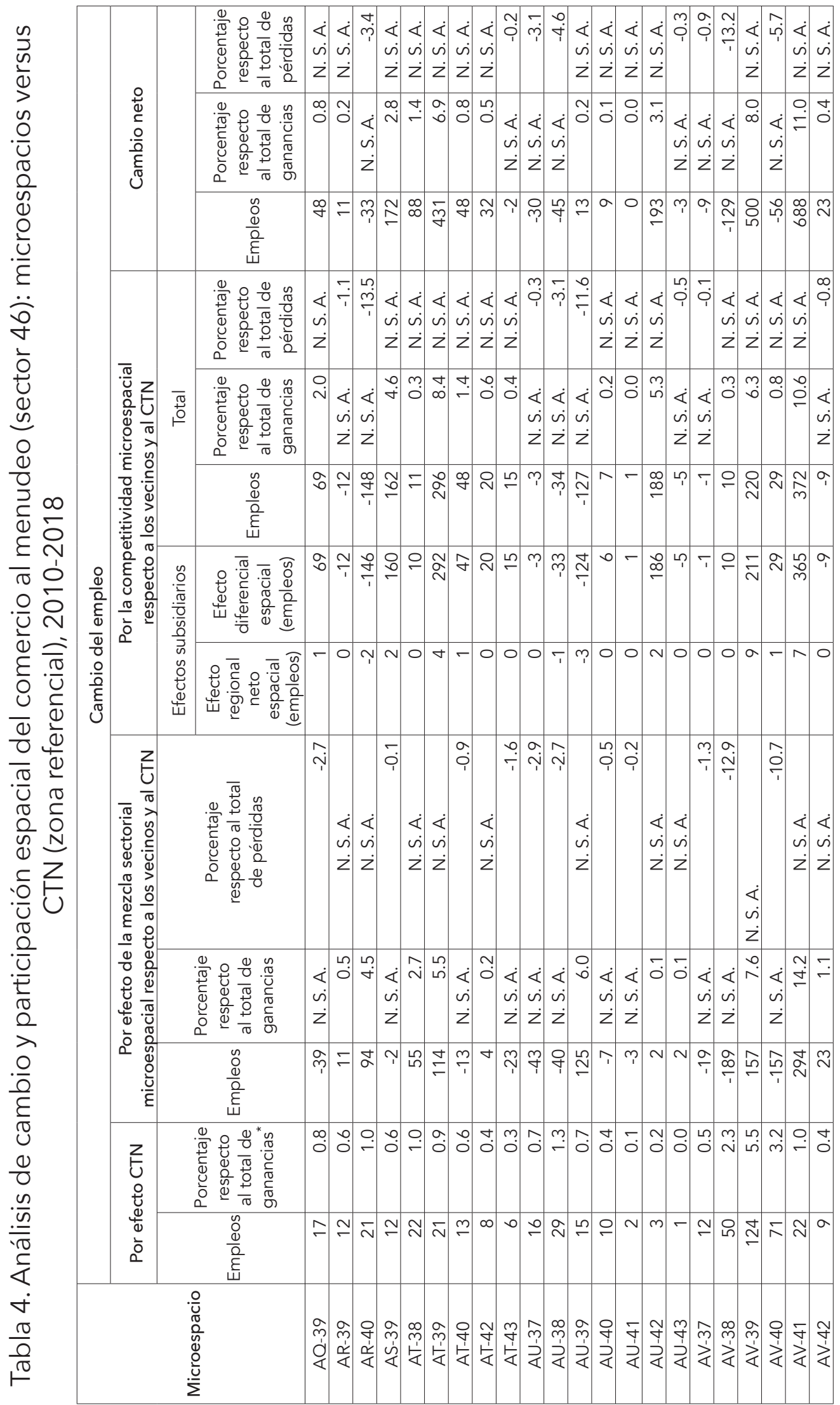




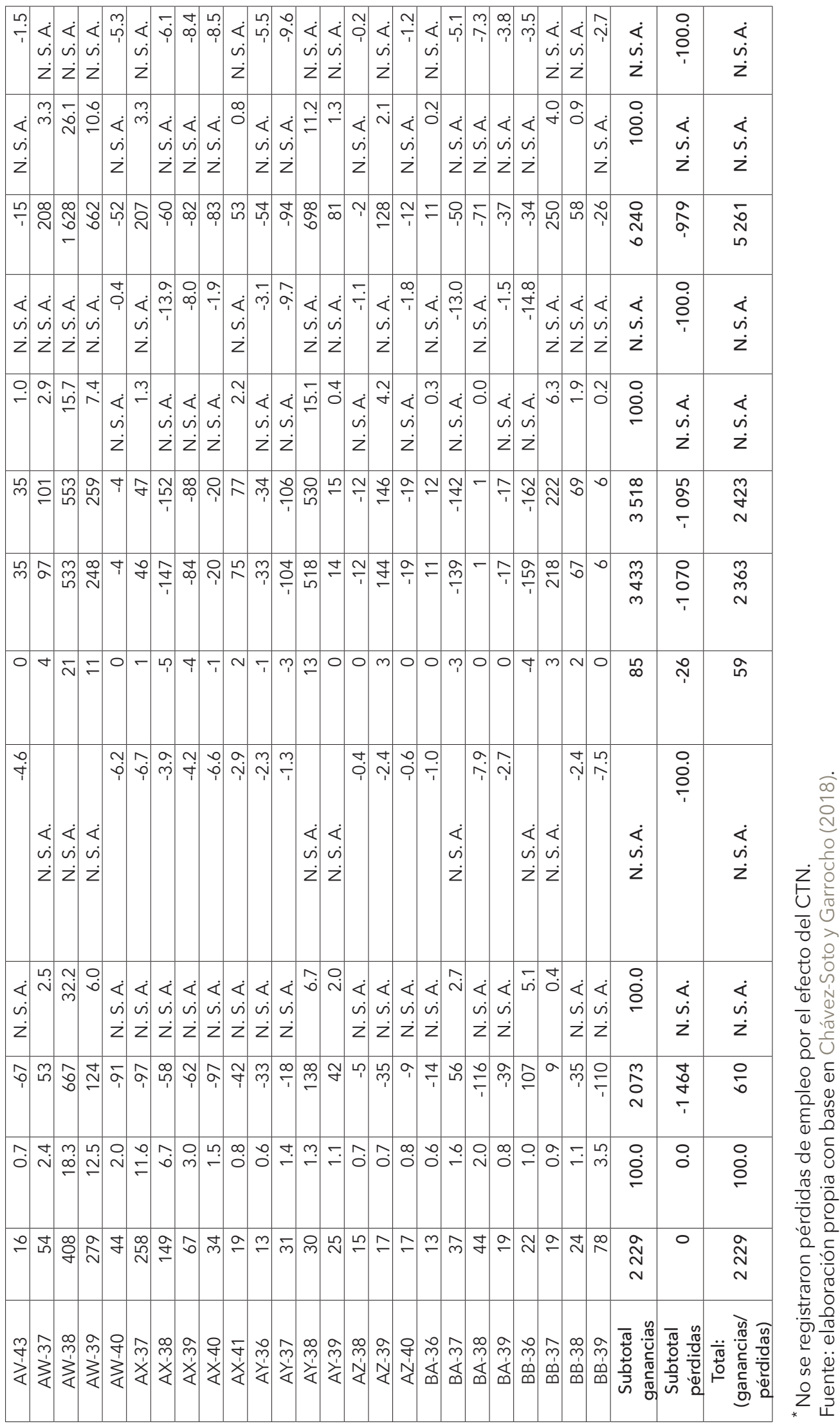


resultó favorable (138 empleos, en parte porque ahí se localizan magnetos de pequeños negocios: sanatorios, escuelas), pero el efecto más importante fue el de la competitividad microespacial (de manera directa respecto a sus vecinos y de forma indirecta respecto al CTN), que creó 530 empleos (13 empleos debido al ERNE y 518 al EDE). El valor del EDE es interesante: indica que AY-38 tiene ventajas competitivas sobre sus vecinos, como AY-39 y AZ-39, y también sobre el CTN.

El microespacio que más empleos perdió en comercio minorista fue AV-38 (véanse figura 3 y tabla 4). Su importancia simbólica es enorme, ya que es sede de los palacios ejecutivo, legislativo y judicial, de la Catedral, del gran Teatro Morelos y de las instituciones educativas importantes. En AV-38, la inercia del CTN y sus vecinos (efecto CTN-V) fue positiva: impulsó la creación de 50 empleos, pero la competitividad microespacial fue casi nula (contribuyó con diez empleos, por el efecto EDE), lo que implica problemas, porque evidencia desventajas competitivas respecto a sus vecinos y en relación con el CTN. La situación es más decadente con su mezcla sectorial, ya que concentra su empleo en sectores decadentes del CTN y sus vecinos, lo que lo hizo perder 189 empleos. Al final, el cambio neto espacial fue negativo: -129 empleos. En descargo del AV-38 se debe decir que su vocación no es comercial, sino simbólica, como sede de los edificios públicos más importantes de la ciudad.

Entre los microespacios perdedores, también es muy interesante examinar su competitividad. Es decir, el efecto de sus desventajas competitivas (o competitividad microespacial negativa). El microespacio que más empleos perdió por este efecto, fue BB-36 (véase tabla 4). Se trata de un microespacio con grandes problemas locacionales: se ubica en la periferia del noreste del CTN, junto a vías de ferrocarril (véase figura 4). Por efecto CTN-V debió haber ganado 22 empleos; y por su mezcla sectorial, 107 (los negocios que quedan coinciden con las actividades dinámicas de sus vecinos y del CTN), pero registra importantes desventajas competitivas que le hicieron perder 162 empleos (-4 por ERNE y -159 por ENE). Al final, su cambio neto fue -34 empleos.

Servicios de profesionales (sectores $54,56,62$ )

Como ya se vio, durante el periodo de estudio los servicios profesionales emigraron del CTN. ¿Qué microespacios se sostienen en la competencia? ¿En qué partes del CTN se concentró la debacle? ¿Por qué?

Cuatro microespacios, de los 47 del CTN, crearon más de 100 empleos en servicios profesionales: AR-40 (422 empleos), V-42 (421), AY-39 (173), BA-37 (114) (véanse figura 3 y tabla 4). Los dos primeros crearon más de $50 \%$ del empleo en servicios profesionales que se localizó en el CTN. El efecto dominante en AR-40 fue el de la competitividad microespacial: 413 empleos (98\% del total del microespacio). Por ERNE sólo se crearon cinco empleos (lo que indica que su estructura ocupacional es muy distinta a la de sus vecinos y a la del CTN), pero por el EDE se produjeron 408 (significa que este microespacio ofrece importantes ventajas competitivas a los servicios profesionales sobre sus vecinos y el (TN). En este microespacio se localizan diversas instalaciones del equipo profesional de fútbol los Diablos Rojos. También se encuentran las oficinas 
del Instituto de Seguridad Social del Estado de México y Municipios (ISSEMYM), que ocupa a cientos de profesionales. Los resultados indican que AR-40 ofrece ventajas competitivas a las organizaciones que los ocupan, pero también a los profesionales independientes que tienen sus despachos o consultorios. La localización de este microespacio, en la periferia oeste del CTN (muy próximo al campus de la universidad estatal, que tiene 77.5 mil estudiantes) y el peso dominante de su competitividad microespacial, explican que los beneficios de ser parte del CTN (efecto CTN-V y de la mezcla sectorial) son casi nulos para AR-40 (véase tabla 4): el CTN es el beneficiario de tener a AR-40.

Figura 3. Análisis de cambio y participación espacial del comercio al menudeo (sector 46): Microespacios versus CTN (zona referencial), 2010-2018
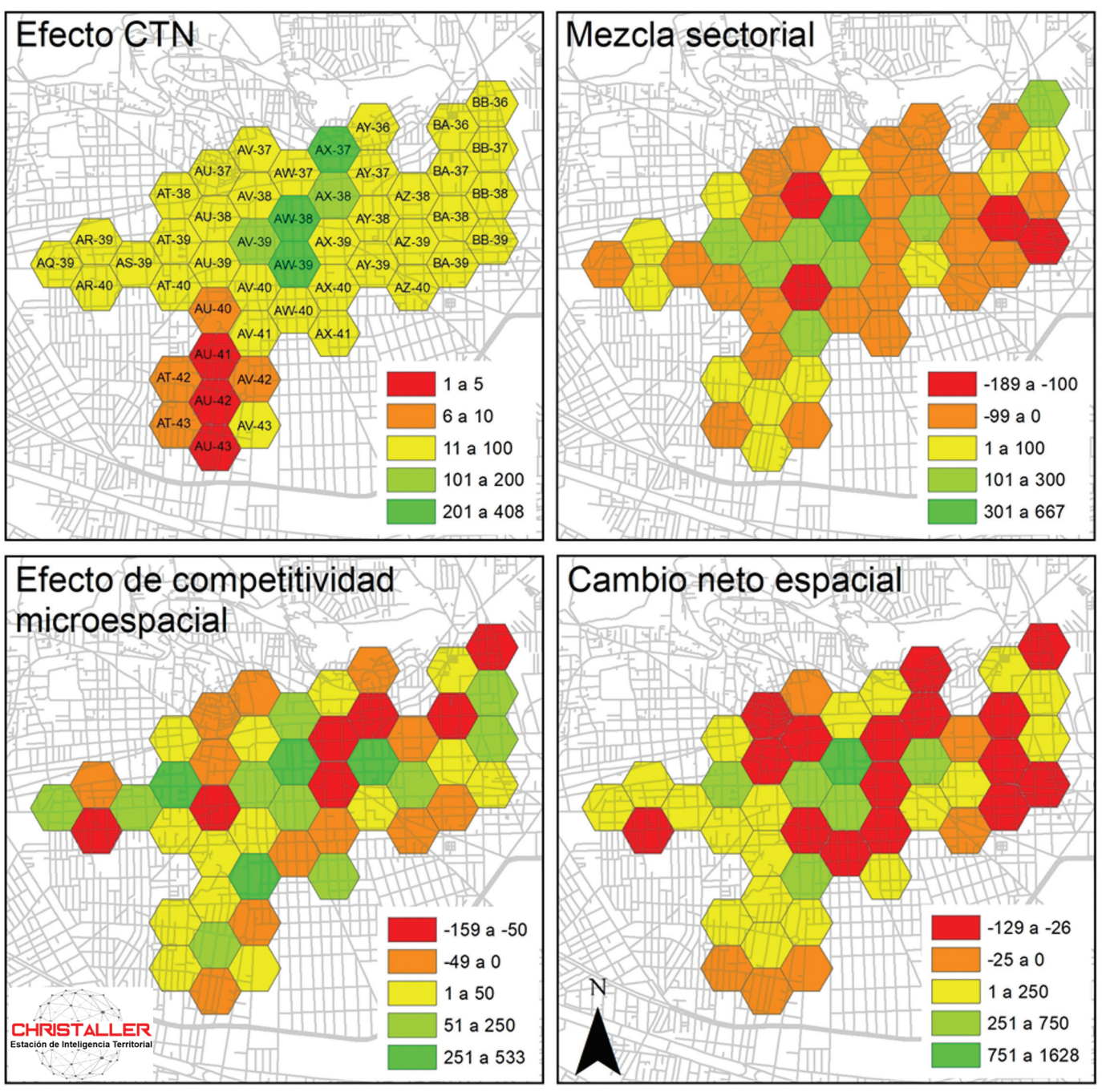

Fuente: elaboración propia con base en Chávez-Soto y Garrocho (2018). 


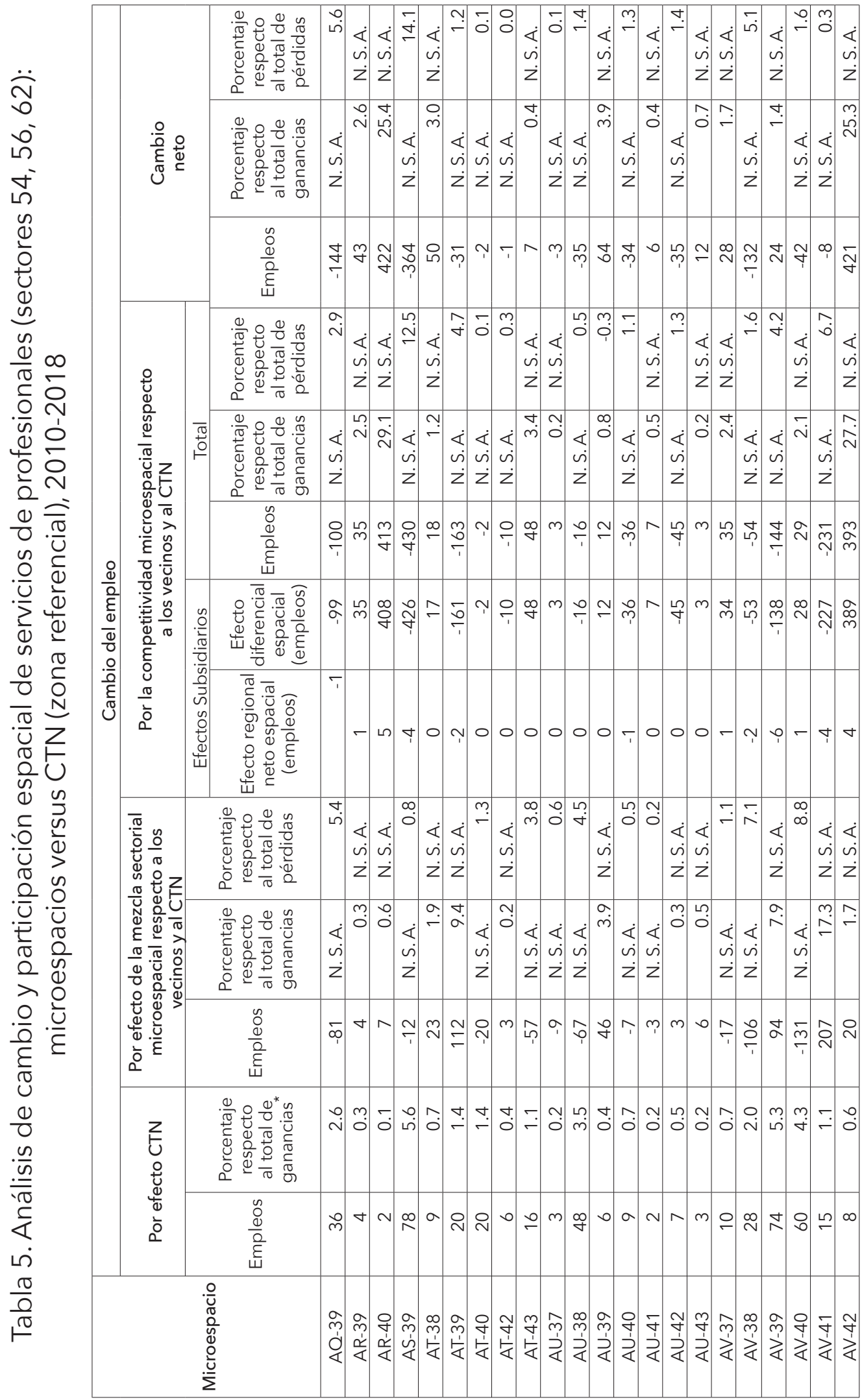




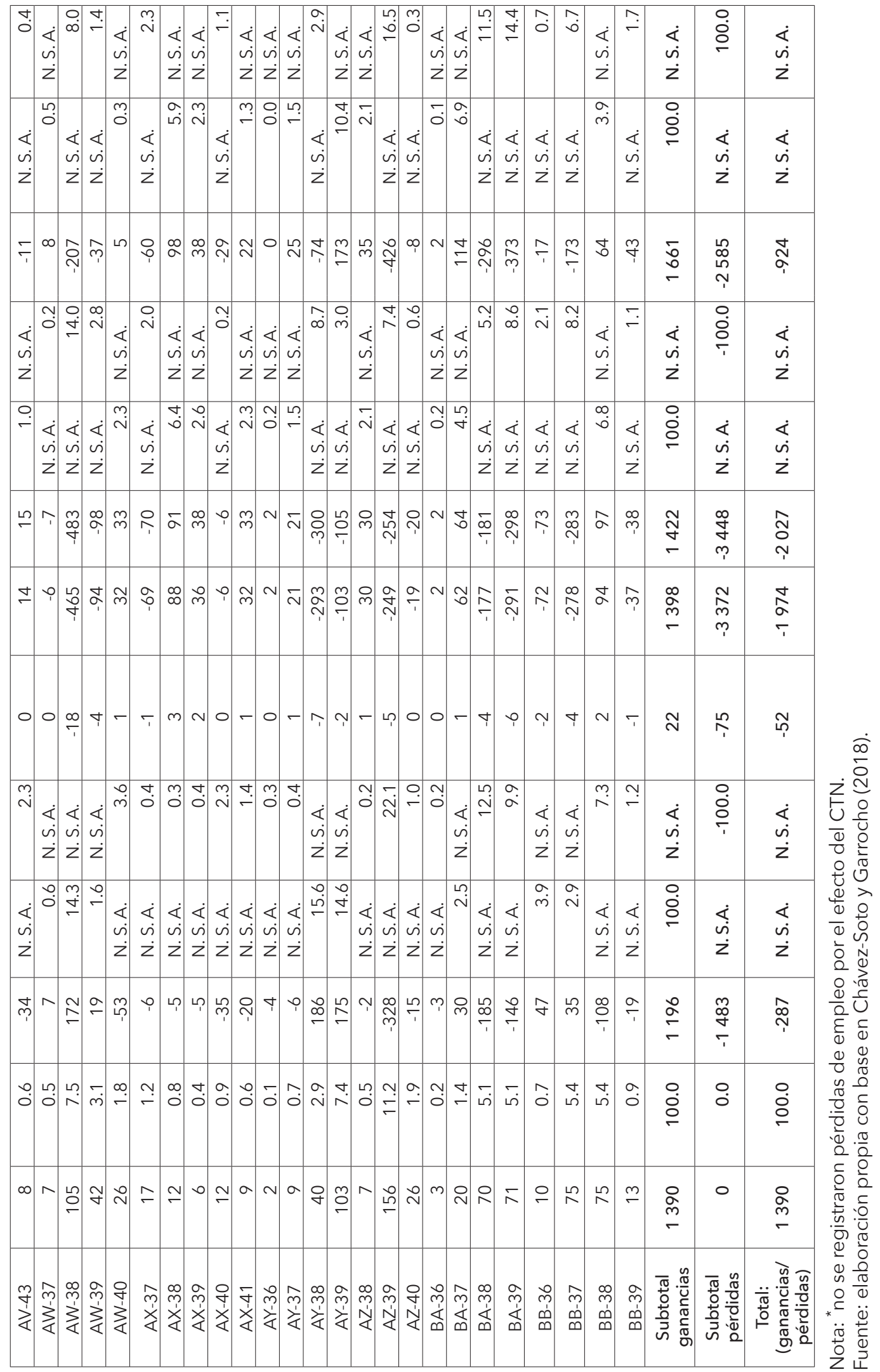


Figura 4. Análisis de cambio y participación espacial de servicios de profesionales (sectores 54, 56, 62): microespacios versus CTN (zona referencial), 2010-2018
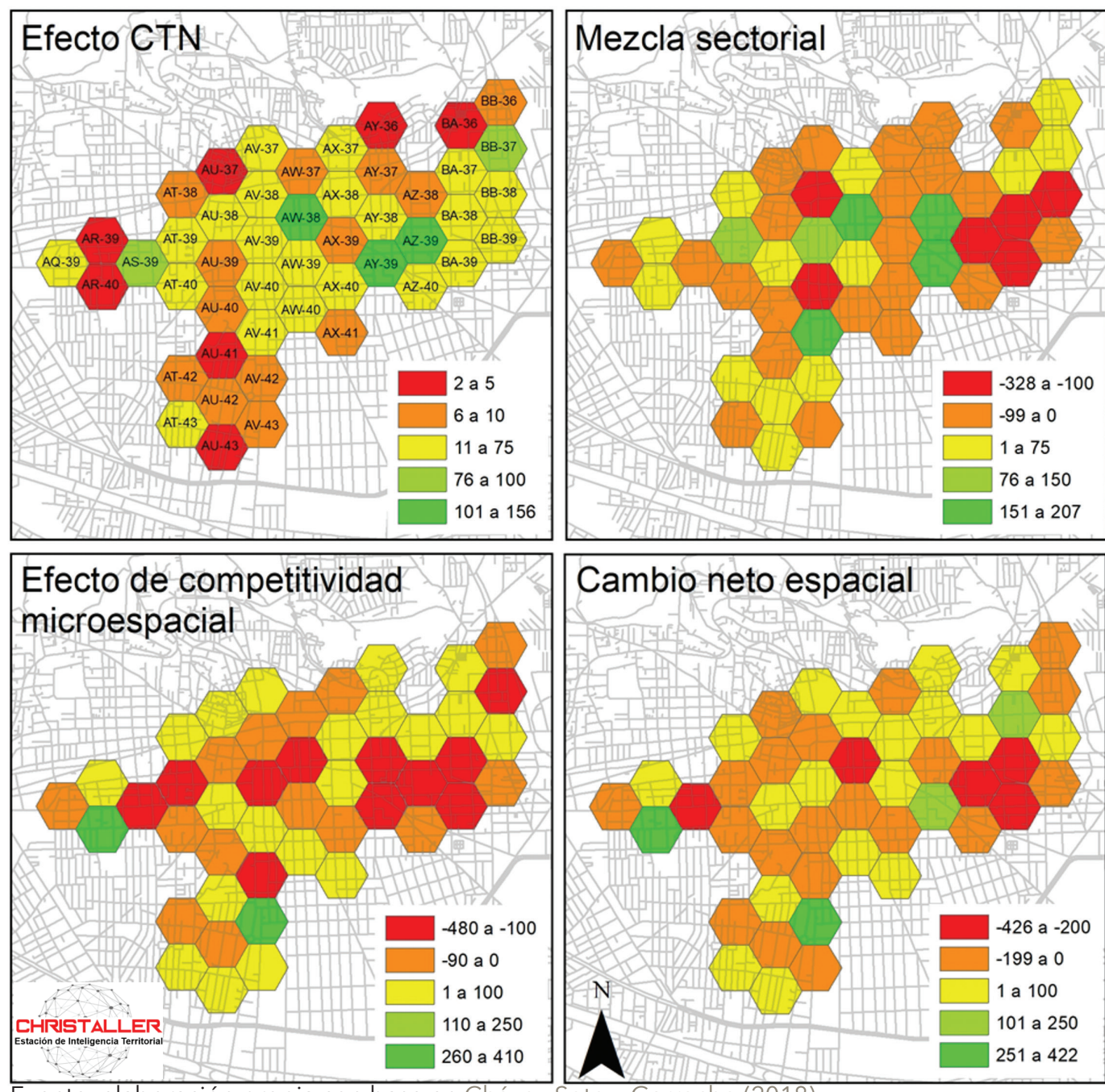

Fuente: elaboración propia con base en Chávez-Soto y Garrocho (2018).

Tabla 6. Cambio del empleo en el CTN y el área metropolitana de Toluca, 2010-2018

\begin{tabular}{|c|c|c|c|c|c|c|c|}
\hline \multirow{3}{*}{$\begin{array}{c}\text { Clave } \\
\text { del } \\
\text { sector }\end{array}$} & \multirow{3}{*}{ Descripción } & \multicolumn{4}{|c|}{ Cambio en el empleo } & \multirow{2}{*}{\multicolumn{2}{|c|}{ Diferencia }} \\
\hline & & \multicolumn{2}{|c|}{$\begin{array}{l}\text { Centro tradicional } \\
\text { de negocios }\end{array}$} & \multicolumn{2}{|c|}{\begin{tabular}{|c} 
Área metropolitana de \\
Toluca
\end{tabular}} & & \\
\hline & & Absoluto & $\begin{array}{c}\text { Tasa de } \\
\text { cambio } \\
\text { (porcentaje) }\end{array}$ & Absoluto & $\begin{array}{c}\text { Tasa de cambio } \\
\text { (porcentaje) }\end{array}$ & Absoluta & $\begin{array}{l}\text { Tasa de cambio } \\
\text { (porcentaje) }\end{array}$ \\
\hline 21 & Minería & 0 & 0 & 210 & 6.4 & 210 & 6.4 \\
\hline 22 & Energía & 20 & 40 & 1361 & 30.8 & 1341 & -9.2 \\
\hline 23 & Construcción & 61 & 5.6 & 2500 & 28.4 & 2439 & 22.8 \\
\hline 31 & $\begin{array}{c}\text { Industria } \\
\text { alimentaria }\end{array}$ & 58 & 6 & -6450 & -17 & -6508 & -23 \\
\hline
\end{tabular}




\begin{tabular}{|c|c|c|c|c|c|c|c|}
\hline 32 & $\begin{array}{c}\text { Industria } \\
\text { maderera }\end{array}$ & -79 & -7.3 & 8808 & 39.1 & 8887 & 46.4 \\
\hline 33 & $\begin{array}{c}\text { Industria } \\
\text { metálica } \\
\text { básica }\end{array}$ & -99 & -27.6 & 4827 & 20.6 & 4926 & 48.2 \\
\hline 43 & $\begin{array}{c}\text { Comercio } \\
\text { mayorista }\end{array}$ & 275 & 18 & 10942 & 57.5 & 10667 & 39.5 \\
\hline 46 & $\begin{array}{c}\text { Comercio } \\
\text { minorista }\end{array}$ & 5261 & 42.5 & 34161 & 30.3 & 28900 & -12.2 \\
\hline 52 & Financieros & 534 & 108.8 & 2403 & 50.1 & 1869 & -58.7 \\
\hline 53 & Inmobiliarios & 67 & 15.4 & -42 & -0.6 & -109 & -16 \\
\hline 54 & Despachos & -164 & -8.4 & 1157 & 11.6 & 1321 & 20 \\
\hline 56 & Asesores & 2 & 0.1 & 5618 & 31.9 & 5616 & 31.8 \\
\hline 61 & Educación & 836 & 14 & 6139 & 15.3 & 5303 & 1.3 \\
\hline 62 & Consultorios & -762 & -21.9 & 4260 & 21 & 5022 & 42.9 \\
\hline 71 & Cultura & 593 & 107 & 2109 & 31 & 1516 & -76 \\
\hline 72 & $\begin{array}{c}\text { Restaurantes } \\
\text { y hoteles }\end{array}$ & 622 & 16.1 & 7122 & 24.4 & 6500 & 8.3 \\
\hline 81 & $\begin{array}{c}\text { Otros } \\
\text { servicios }\end{array}$ & -41 & -1.2 & 1640 & 4.8 & 1681 & 6 \\
\hline & Total & 7184 & 11.8 & 86765 & 21.6 & 79581 & 9.8 \\
\hline
\end{tabular}

Fuente: elaboración propia con base en Chávez-Soto y Garrocho (2018).

El otro ganador de empleo en servicios profesionales fue el microespacio AV42 (421 empleos). Al igual que AR-40, tiene una localización periférica, pero al sur del CTN (véanse figura 4 y tabla 4). Lo cruzan dos vialidades con gran actividad económica y buena imagen urbana (Venustiano Carranza y Colón). La calle Colón es la sede de la residencia oficial del gobernador del estado y también funciona como oficinas gubernamentales de alto nivel. La buena calidad física de la zona y su seguridad ofrecen ventajas competitivas a los profesionales independientes. Este microespacio casi no se beneficia de ser parte del CTN (véanse los bajos valores de los efectos CTN-V y de mezcla sectorial). Lo que se confirma con su notable competitividad microespacial: 393 empleos, de los cuales 389 se derivan de las ventajas competitivas de este microespacio respecto a sus vecinos (EDE). Como con AR-40, el CTN se beneficia de tener a AV-42: genera flujos de peatones que le dan vitalidad.

Entre los grandes perdedores de empleo en servicios profesionales, destaca AZ-39, que perdió 426 y que forma un clúster de microespacios con BA-38 (-296 empleos) y BA-39 (-373). A estos tres habría que sumarle el AS-39, que perdió 364 empleos (véanse figura 4 y tabla 5). Estos cuatro microespacios son responsables de la salida de 1456 profesionales del CTN, equivalente a 56\% del éxodo. El clúster perdedor se localiza en la periferia este del CTN, en la parte decadente de las calles Isabel la Católica y Sor Juana Inés de la Cruz, que ha sido reportada como zona de poco tráfico de compradores potenciales (Garrocho y Flores, 2009). Por efecto del CTN, estos tres microespacios deberían 
haber creado 297 empleos, que fueron borrados por las pérdidas debidas a su pobre mezcla sectorial (-659 empleos) y a sus desventajas competitivas (-733 empleos). Algo similar ocurre con el AS-39. La inercia del CTN debió haber impulsado la creación de 78 empleos en ese microespacio, pero fueron destruidos, sobre todo por sus desventajas competitivas respecto a sus vecinos y al CTN (véase efecto EDE), que causaron la salida de 426 empleos. En apariencia, AS39 debería ofrecer ventajas competitivas a profesionales liberales, ya que está próximo a hospitales, clínicas y tribunales, pero no es así.

En la tabla 6 se muestra un resumen del cambio en el empleo de los sectores económicos que se consideraron en el ACPE para el CTN y el área metropolitana de Toluca.

\section{Conclusiones, aportaciones, recomendaciones}

Este trabajo explica la dinámica del empleo en el CTN del AMT entre 2010 y 2018, en el marco del análisis de cambio y participación (tradicional y espacial). En específico, ofrece respuestas a las preguntas: ¿cuánto, dónde, cuándo, en qué sectores y por qué cambió el empleo en el CTN y en sus espacios interiores? Se consideraron cuatro escalas de estudio: metropolitana, CTN, espacios interiores del CTN (microespacios) y conjuntos de microespacios vecinos (zonas vecinales).

Se rastrearon las causas directas e indirectas del cambio del empleo en el CTN: 1) efecto metropolitano (la inercia del cambio del empleo en la ciudad o zona de referencia general); 2) efecto del CTN y de los vecinos de cada microespacio (inercia del cambio del empleo de la zona de estudio y zonas referenciales vecinales); 3) mezcla sectorial (especialización de los microespacios en sectores dinámicos o lentos del CTN y de sus zonas vecinales); 4) competitividad microespacial (competitividad de cada microespacio para atraer empleos de ciertos sectores de actividad); 5) efecto regional neto espacial (efecto directo de la inercia del cambio del empleo en las zonas vecinales, pero también el efecto indirecto de la inercia del cambio del empleo en el CTN); 6) efecto diferencial espacial (el cambio del empleo debido a la competitividad microespacial respecto a las zonas vecinales y al CTN).

Cada causa de cambio en el empleo ofrece insumos para diseñar estrategias e instrumentar acciones público-privadas que reactiven la economía del CTN. Este trabajo las localiza por microespacio y sector, lo que facilita articularlas en el tiempo. Se identifican microespacios claves que deben ser atendidos para recuperar y fortalecer funciones centrales del CTN y otros centros exitosos de los cuales depende la vitalidad de la zona de estudio. Los resultados arrojan luz para perfilar una agenda de investigación de estudios cualitativos, con el fin de obtener información con mayor detalle para develar las causas de las causas del cambio en el empleo.

La agenda de investigación puede cohesionarse en torno a preguntas estratégicas: ¿qué hace a un microespacio más competitivo que otro?; ¿por qué ciertos microespacios sufren notables desventajas competitivas?; ¿cómo afecta 
la inercia del cambio del empleo en distintas escalas espaciales a microespacios concretos?; ¿es posible adaptar al CTN el diseño básico de las plazas comerciales planificadas, que se articulan por tiendas ancla?; ¿se podrían relocalizar ciertas oficinas públicas o reforzar ciertos microespacios para que desempeñaran el rol de atractores ancla, con el fin de modular el tráfico de compradores potenciales en el CTN?; ¿esta alternativa podría incluir el empleo informal, tan importante en América Latina?

Este trabajo ofrece información clave para fortalecer el CTN como lugar de funciones centrales, símbolo que cohesiona y es motor de desarrollo. Si además contribuye a concebir el CTN como un gran proyecto urbano permanente (Carrión, 2010), la tarea estará cumplida.

\section{Referencias}

Albertos, J. (2019). Economic trajectories of the Spanish regions in the post-crisis scenario: neighborhood, specialization and agglomeration effects. Revista de Estudios Andaluces, (38), 209-211. doi: http://dx.doi.org/10.12795/ rea.2019.i38.01

Anselin, L. (2013). From SpaceStat to CyberGIS: twenty years of spatial data analysis software. En C. Garrocho (ed.), Advances in Commercial Geography: Prospects, Methods, and Applicationss (pp. 143-174). Ciudad de México: El Colegio Mexiquense.

Berry, B. J. L. (1964). Cities as systems within systems of cities. Papers of the Regional Science Association, 13(1), 146-163.

Berry, B. J. L. (2013). Commercial and economic geography: past and future. En C. Garrocho (ed.), Advances in Commercial Geography: Prospects, Methods, and Applications (pp. 43-58). Ciudad de México: El Colegio Mexiquense.

Campos-Alanís, J., Ramírez-Sánchez, L. G., y Garrocho, C. (2020). Inclusión de la variable espacial en la medición de las condiciones relativas de vida en ciudades mexicanas. Papeles de Población, 26(103), 53-88. doi: http:// dx.doi.org/10.22185/24487147.2020.103.03

Carrión, F. (2010). El laberinto de las centralidades históricas en América Latina. El centro histórico como objeto de deseo. Quito: Ministerio de Cultura.

Casado, J. M. (2012). La estructura policéntrica de los mercados laborales locales de la zona metropolitana del Valle de México. Investigaciones Geográficas (79), 97-118.

Chávez-Soto, T., y Garrocho, C. (2018). Christaller®: Estación de Inteligencia Territorial. Geografía y Sistemas de Información Geográfica (GEOSIG), 10(10), 29-50.

Coulomb, R. (2018). Sustentabilidad de la centralidad urbana e histórica. Una reflexión desde el centro histórico de la ciudad de México. Quivera, Revista de Estudios Territoriales, 10(2), 29-49.

Flores, A. J., Solís, S. Y., y Álvarez-Aros, E. L. (2020). Contextualization of economic activity and innovation perspective in Reynosa, Mexico. A shift-sha- 
re analysis 2004-2014. Revista Espacios, 41(03), 21. Recuperado de http:// www.revistaespacios.com/a20v41n03/20410321.html\#iden5

Flores, Z., Garrocho, C., Chávez, T., y Álvarez-Lobato, J. A. (2013). Microspatial analysis of tertiary activities in the traditional business center of a big Mexican city. En C. Garrocho (ed.), Advances in Commercial Geography: Prospects, Methods, and Applications (pp. 239-270). Ciudad de México: El Colegio Mexiquense.

Fuenzalida, M., Buzai, G., Moreno Jiménez, A., y García de León, A. (2015). Geografía, geotecnología y análisis espacial: tendencias, métodos y aplicaciones. Chile: Triángulo.

Gallo, J. Le, y Kamarianakis, Y. (2011). The evolution of regional productivity disparities in the European Union from 1975 to 2002: a combination of shift-share and spatial econometrics. Regional Studies, 45(1), 123-139. doi: https: / / doi.org/10.1080/00343400903234662

Garrocho, C. (2003). La teoría de interacción espacial como síntesis de las teorías de localización de actividades comerciales y de servicios. Economía, Sociedad y Territorio, 4(14), 203-251. doi: https://doi.org/10.22136/ est002003426

Garrocho, C. (2005). Localización, localización y localización: el manejo del espacio en la competencia entre centros comerciales. Estudios Demográficos y Urbanos, 20(3), 449-494. doi: https://doi.org/10.24201/edu.v20i3.1207

Garrocho, C., y Campos, J. (2007). Dinámica de la estructura policéntrica del empleo terciario en el área metropolitana de Toluca, 1994-2004. Papeles de Población, 13(52), 109-135.

Garrocho, C., y Campos, J. (2009). Estructura espacial del empleo terciario en el área metropolitana de Toluca, 1993-2003. En G. Garza y L. Sobrino (coords.), Evolución del sector servicios en ciudades y regiones de México (pp. 827-875). Ciudad de México: El Colegio de México.

Garrocho, C., y Campos, J. (2013), Réquiem por los indicadores no espaciales de segregación residencial. Papeles de Población, 19(77), 269-300.

Garrocho, C., y Flores, Z. (2009). Delimitación del centro tradicional de comercio y servicios de la zona metropolitana de Toluca. Papeles de Población, 15(61), 233-274.

Giuliano, G., Redfearn, C., Agarwal, A., Li, C., y Zhuang, D. (2007). Employment concentrations in Los Angeles, 1980-2000. Environment and Planning A, 39(12), 2935-2957. doi: https://doi.org/10.1068/a393

Giuliano, G., Redfearn, C., Agarwal, A., y He, S. (2012). Network accessibility and employment centres. Urban Studies, 49(1), 77-95. doi: https://doi. org/10.1177/0042098011411948

Goodall, B. (1987). The Penguin Dictionary of Human Geography. Londres: Penguin Reference Books.

Instituto Nacional de Estadística y Geografía (INEGI). (2019). Directorio Estadístico Nacional de Unidades Económicas (20014 y 2018). México: INEGI. Recuperado de https: / /www.inegi.org. mx/app/descarga/?ti=13\&ag=01

Ives, B., Cossick, K., y Adams, D. (2019). Amazon Go: disrupting retail? Journal of Information Technology Teaching Cases, 9(1), 2-12. doi: https://doi. org/10.1177/2043886918819092 
Jones, K., y Simmons, J. W. (1990). Retail Environment: Location, Location, Location. Nelson, Canada: Van Nostrand Reinhold.

Kivi, L. (2019). Spatial Interactions of Regional Labor Markets in Europe. Tartu: Universidad de Tartu. doi: http://dx.doi.org/10.2139/ssrn.3330778

Lievanos, J., y Villar, A. (2015). Transformación histórica de la centralidad de Toluca: de la ciudad monocéntrica al espacio metropolitano policéntrico. 20 Encuentro Nacional sobre Desarrollo Regional en México, Asociación Mexicana de Ciencias para el Desarrollo Regional (AMECIDER)-Centro Regional de Investigaciones Multidisciplinarias (CRIM) de la Universidad Autónoma de México (UNAM), pp. 1-24. Recuperado de http://ru.iiec.unam.mx/3050/1/ Eje9-097-Lievanos-Villar.pdf

Loveridge, S., y Selting, A. (1998). A review and comparison of shift-share identities. International Regional Science Review, 21(1), 37-58. doi: https: / / doi. org/10.1177/016001769802100102

Mariscal, M. , y Montaño, R. (2018). Policentrismo y jerarquía de localidades de la región "Altos Sur" de Jalisco, 2010. ACE: Architecture, City, and Environment (38), 235-262. doi: http://dx.doi.org/10.5821/ace.13.38.5360

Melchor-Ferrer, E. (2020). Determinants of labor productivity growth in Spanish and Portuguese regions: a spatial shift-share approach. The Annals of Regional Science, 65(1), 45-65. doi: https://doi.org/10.1007/s00168-019-00973-4

Mo, S. W., Lee, K. B., Lee, Y. J., y Park, H. G. (2020). Analysis of import changes through shift-share, location quotient and BCG techniques: Gwangyang Port in Asia. The Asian Journal of Shipping and Logistics. doi: https://doi. org/10.1016/j.ajsl.2020.01.001

Montejano-Escamilla, J. A. (2015). ¿Es la ciudad de México policéntrica?: nuevos datos y algoritmos para la detección de centralidades urbanas. Economía, Sociedad y Territorio, 15(48), 333-361.

Muñiz, I., Sánchez, V., y García-López, M. (2015). Estructura espacial y densidad de población en la ZMVM 1995-2010: evolución de un sistema urbano policéntrico. EURE (Santiago), 41(122), 75-102.

Nazara, S., y Hewings, G. (2003). Towards regional growth decomposition with neighbor's effect: a new perspective on shift share analysis. Regional Economics Application Laboratory (21), 2-18.

Nazara, S., y Hewings, G. J. (2004). Spatial structure and taxonomy of decomposition in shift-share analysis. Growth and Change, 35(4), 476-490. doi: https://doi.org/10.1111/j.1468-2257.2004.00258.x

Niño, C., Arballo, R., y Sández, P. (2003). Evolución del sector manufacturero bajacaliforniano durante la transición hacia la apertura económica (19751993): una perspectiva sistémica. Estudios Fronterizos, 48(7), 84-115.

O’Sullivan, A. (2007). Urban Economics. Boston: McGraw Hill-Irwin.

Patterson, M. (1991). A note on the formulation of a full analogue regression model of the shift-share method. Journal of Regional Science, 31(2), 211216. doi: https://doi.org/10.1111/j.1467-9787.1991.tb00143.x

Piacentino, D., Espa, G., Filipponi, D., y Giuliani, D. (2017). Firm demography and regional development: evidence from Italy. Growth and Change, 48(3), 359-389. doi. https://doi.org/10.1111/grow.12172 
Psycharis, Y., Kallioras, D., y Pantazis, P. (2018). Employment changes and regional resilience: an application of trade adjusted shift-share analysis to the Greek regions. En T. Baycan y H. Pinto (eds.), Resilience, Crisis, and Innovation Dynamics (pp. 188-210). Massachusetts: Edward Elgar Publishing.

Ramajo, H., y Márquez, P. (2008). Componentes espaciales en el modelo shift-share. Una aplicación al caso de las regiones peninsulares españolas. Estadística Española, 50(168), 247-272.

Ramírez-Sánchez, L. G., (2020). Centro tradicional de negocios de Toluca, 20002010: ¿oportunidad o decadencia? Economía, Sociedad y Territorio, 20(64), 755-786. doi: https://doi.org/10.22136/est20201613

Rendón, L., Andrés, R., y Mejía, P. (2019). Shift-share espacial del empleo manufacturero municipal. zonas metropolitanas: Valle de México y Toluca, 20082013. Economía, Sociedad y Territorio, 19(59), 1213-1242. doi: https:// doi. org/10.22136/est20191248

Rice, G. A. (2009). Central Business District. En R. Kitchin y N. Thrift (eds.), International Encyclopedia of Human Geography (pp. 18-24). Ámsterdam: Elsevier.

Richardson, H. (1978). The state of regional economics: a survey article. International Regional Science Review, 3(1), 1-48. doi: https://doi. org/10.1177/016001767800300101

Rojas, L. R., Mejía, P., y Díaz, M. (2021). Empleo manufacturero de los estados del centro de México. Análisis shift and share tradicional y con modificación de estructuras, 1998-2018. Paradigma Económico, 13(1), 5-34.

Shearmur, R., Garrocho, C., Álvarez-Lobato, J., y Chávez, T. (2015). Hacia una geografía de las actividades económicas en la Ciudad de México: métodos, conceptos, cultura y subjetividad. En C. Garrocho y G. Buzai (coord.), Geografía aplicada en Iberoamérica: avances, retos y perspectivas (pp. 431472). Ciudad de México: El Colegio Mexiquense.

Simmons, J. (2013). The evolution of commercial structure in the North American city: a Toronto case study. En C. Garrocho (ed.), Advances in Commercial Geography: Prospects, Methods, and Applications (pp. 175-206). Ciudad de México: El Colegio Mexiquense.

Simmons, J., Garrocho, C., y Kamikihara, S. (2016). La estructura del comercio al por menor en la Ciudad de México. En G. Aguilar (coord.), La Ciudad de México en el siglo XXI (pp. 415-424). Ciudad de México: UNAM-Porrúa.

Simmons, J., Garrocho, C., Kamikihara, S., y Campos, J. (2018). The evolving retail structure of Mexico City. Papers in Applied Geography, 4(3), 305-325. doi: https://doi.org/10.1080/23754931.2018.1486731

Suárez-Lastra, M. , y Delgado-Campos, J. (2010). Patrones de movilidad residencial en la Ciudad de México como evidencia de co-localización de población y empleos. EURE, 36(107), 67-91. doi: http://dx.doi.org/10.4067/S025071612010000100004

Tobler, W. R. (1970). A computer movie simulating urban growth in the Detroit region. Economic Geography, 46(1), 234-240.

Valdez, R. (2018). Impacto de la proximidad geográfica en los cambios del empleo manufacturero en México: análisis shift-share espacial. Frontera Norte, 30(59), 155-184. doi: https://doi.org/10.17428/rfn.v30i59.1137 
Vilchis, I., Garrocho, C., y Chávez, T. (2021). Dinámica del empleo en sectores intensivos en uso del conocimiento en la megalópolis del Valle de México, 2014-2018. Manuscrito inédito.

Wrigley, N. (2013). Towards a policy engaged retail geography. En C. Garrocho (ed.), Advances in Commercial Geography: Prospects, Methods, and Applications (pp. 59-94). Ciudad de México: El Colegio Mexiquense.

Zacommer, G., y Mason, P. (2011). A new spatial shift-share decomposition for the regional growth analysis: a local study of the employment based on Italian business statistical register. Statistical Methods \& Applications, 20(3), 329-356. doi: https://doi.org/10.1007/s10260-011-0160-5 